\title{
Article \\ A Prediction Method with Altering Equivalent Stiffness for Damping Evaluation of Shrouded Bladed Disk Dynamic Systems
}

\author{
Shimin Gao ${ }^{1,2}$, Yanrong Wang $1,2, * \mathbb{D}$, Zhiwei Sun ${ }^{3}$ and Siyuan Chen ${ }^{1,2}$ \\ 1 School of Energy and Power Engineering, Beihang University, Beijing 100191, China; \\ gaoshimin@buaa.edu.cn (S.G.); csy_0918@buaa.edu.cn (S.C.) \\ 2 Collaborative-Innovation Center for Advanced Aero-Engine, Beihang University, Beijing 100191, China \\ 3 Beijing Power Machinery Institute, CASIC, Beijing 100074, China; 13041125@buaa.edu.cn \\ * Correspondence: yrwang@buaa.edu.cn
}

Citation: Gao, S.; Wang, Y.; Sun, Z.; Chen, S. A Prediction Method with Altering Equivalent Stiffness for Damping Evaluation of Shrouded Bladed Disk Dynamic Systems. Symmetry 2021, 13, 413. https:// doi.org/10.3390/sym13030413

Academic Editor: Zhirabok Alexey

Received: 21 January 2021

Accepted: 2 March 2021

Published: 4 March 2021

Publisher's Note: MDPI stays neutral with regard to jurisdictional claims in published maps and institutional affiliations.

Copyright: () 2021 by the authors. Licensee MDPI, Basel, Switzerland. This article is an open access article distributed under the terms and conditions of the Creative Commons Attribution (CC BY) license (https:// creativecommons.org/licenses/by/ $4.0 /)$.

\begin{abstract}
In turbomachinery bladed disks are typical cyclic symmetric structures where high-cycle fatigue of the blades can easily occur. Increasing the shroud structure is an effective blade vibration reduction method using the dry friction of the shroud contact surface to dissipate vibration energy. During one vibration cycle of the blade, the contact surface of the shroud may have one or several states of stick, slip, and separation due to the different amplitude of blade, which affects not only the damping, but also the stiffness of the system. This paper proposes a method to analyze the damping characteristics of blades with shroud considering the change of equivalent contact stiffness of the shroud by using the finite element method. With a 2D contact model, this method calculates the equivalent damping and obtains the damping characteristic curve to evaluate the damping of shroud. During the design phase, the objective is that when resonance occurs, the shroud can provide the optimal damping ratio under the allowable vibration stress of the blade. The parameter sensitivity of the damping characteristic for one bladed disk with parallel shroud is investigated. It is shown that vibration phase angle, contact stiffness, contact force, friction coefficient significantly influence the damping characteristics.
\end{abstract}

Keywords: dry friction; shroud damping; turbine blade; contact model

\section{Introduction}

Turbine rotor blades in aero-engines are subjected to high centrifugal loads, static stresses caused by thermal loads, and vibration stresses caused by varying loads, which are likely to cause high-cycle fatigue (HCF) of the blades. This makes it necessary to reduce the static stress and control the vibration stress [1]. During the blade operation, the excitation frequency range is wide, and there are many engine orders (EOs), and it is difficult to avoid all resonances. The dry friction damping technology, which dissipates vibration energy through con-tact surface friction, is an effective means to reduce the vibration stress of rotor blades at critical positions [2]. Low-pressure turbine blades often adopt a shroud structure, which can not only reduce gas leakage to improve aerodynamic efficiency, but increase blade stiffness and damping to reduce blade vibration.

Two typical shroud configurations are zigzag and slant. The desired contact pressure distribution can be obtained through pre-twisting or interference during assembly. At the same time, centrifugal force will also change contact pressure during rotation. This paper adopts a slant shroud and each blade has the half-tenon. Two blades are assembled in pairs in the same mortise, as Figure 1, where the initial normal contact force between shrouds can be obtained through interference assembly and centrifugal force. The assessment of shroud depends on the grasp of the dynamics and contact of the bladed disk structure [3]. 


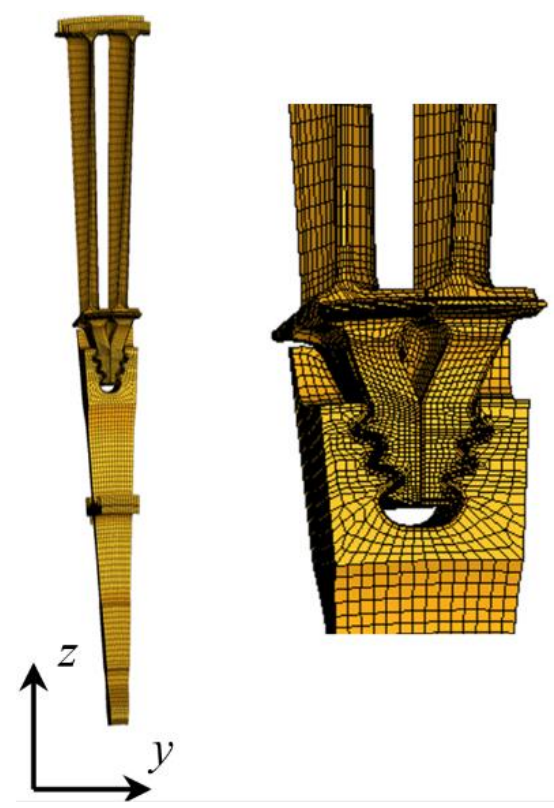

Figure 1. Disk and slant-shroud blades assembled in pairs.

The contact model describes the interaction of an elastic object (usually metal) in dry friction contact, and its relationship with the relative motion of contact surfaces $[4,5]$. Currently, there are multiple contact models: According to the dimension of the relative tangential displacement of the contact surface, it can be divided into 1D model [6,7], 2Dmodel [8,9]; Model with constant [6,8] or variable normal force [7,9]. According to whether to consider local sliding and local stick, they are divided into macro-slip and micro-slip models [10]. Using the developed contact model, the dynamic characteristics of bladed disk can be calculated. The direct time integration (DTI) method is very timeconsuming. In 2008, Phadke and Berger [11] used the finite element tool to calculate the steady-state response of the blade with underplatform dampers by DTI. The response calculation at one excitation frequency required $40 \mathrm{~h}$ at that time. Therefore, researchers have developed faster numerical calculation methods. Considering that the vibration response of bladed disk is periodic, the harmonic balance method (HBM) [12] expands the variables (displacement and force) into Fourier series, combined with the Galerkin method, and the coefficient of the corresponding harmonic term of the equation residual is zero. In this way, the equation of motion is converted from a differential equation in the time domain to an algebraic equation of the Fourier expansion coefficients of the displacement, excitation, and friction, and excitation frequency in the frequency domain, and then this nonlinear equation is solved in the frequency domain. In order to describe contact more effectively, Cameron and Griffin [13] proposed alternating frequency-time (AFT), where after converting the frequency domain displacement to the time domain, the contact forces are solved in the time domain, and then they are converted back to the frequency domain. In order to further reduce the calculation time, the researchers proposed reduced order models (ROM) suitable for different situations to calculate the nonlinear forced response [14-16], such as component mode synthesis (CMS) [17] and frequency response function (FRF) [18]. Some researchers used non-linear modal analysis to deal with the dynamics with dry friction from the perspective of non-conservative systems $[19,20]$. In addition, some other interesting vibration phenomena, such as random vibration by an equivalent linearization method [21] and rub-dynamic characteristics by macroslip friction model [22] of bladed disks were studied.

The amplitude-frequency response curve is often used to evaluate the damping effect of shroud [23]. However, the energy dissipated by shroud contact has been seldom studied. This paper proposes a method for evaluating the damping of turbine blade shroud by the energy method (EM). The goal in design stage is to provide greater damping ratio under 
the allowable vibration stress of the blade. In this method, the equivalent damping ratio is calculated by the proportional relationship between friction energy consumption and the max vibration kinetic energy of the bladed disk. The influence of the shroud at the blade tip on the blade stiffness is considered by the inter-shroud spring. In some vibration modes, the separation phenomenon is easy to occur in the contact state between the slant shrouds. In this paper, the effect of shroud separation on blade stiffness is considered.

In this paper, a method for analyzing the damping characteristics of shrouded turbine blades considering the variation of the contact equivalent stiffness of the shroud is presented. Firstly, the contact model, especially the calculation of the equivalent stiffness of the contact surface, is introduced. Then, the tangential relative displacement of the contact surface is determined by considering the modal analysis results with the equivalent stiffness in three directions. The hysteresis loops of the friction force and the relative displacement are obtained by the contact model, and the equivalent damping of different contact models is calculated using the energy method. Then, the curve of the equivalent stiffness with the amplitude is established, and the influence of the separation on the equivalent stiffness is considered. Finally, the suggestions in the design stage are given, and the parameter sensitivity analysis of damping characteristics is carried out from four aspects: normal and tangential vibration phase angle, contact stiffness, initial contact force and friction coefficient.

\section{Dynamic Model of Shrouded Bladed Disks with Contact}

\subsection{Equation of Motion}

In this paper, a disk with 94 slant shrouded blades is considered. Two blades are assembled in pairs in the same mortise of the disk through two half-mortise structures. By cyclic symmetric boundary conditions, the dynamics of the tuned bladed disk can be analyzed by a single sector [24,25], which greatly reduces the amount of calculation. The bladed disk structure is divided into 47 sectors, and each sector contains a pair of blades assembled in the same mortise. The equation of motion (EoM) of one sector in a finite element model with contact is:

$$
M \ddot{u}+C \dot{u}+K u=f_{e}-f_{c}
$$

where $M, C$ and $K$ are the mass, damping and stiffness matrices, respectively. $f_{\mathrm{e}}$ is the excitation vector. $f_{\mathrm{c}}$ is the contact force vector. $f_{\mathrm{c}}$ is not zero only in the degree of freedom of the contact surface. This paper assumes that the damping provided by the root is small [26], and only the damping provided by the shroud is analyzed.

\subsection{Contact Model}

The contact law describes the relationship between the contact force of the contact surface, that is, the tangential friction force and the normal force, and the relative displacement of the contact surface, which is directly related to the friction energy consumption of the system. In this paper, a pair of contact nodes is used to model the contact between shrouds. In the contact local coordinate system, the 3D relative motion of the contact node pair can be decomposed into the normal relative motion out of the plane and the two mutually perpendicular relative motions in the plane. However, this paper focuses on the evaluation method for damping, therefore the simplified contact model is adopted to speed up the calculation.

The local coordinate system of the shroud contact is shown as Figure 2. Because of the 2D contact model, it is necessary to specify the normal and tangential directions of the contact surface. The normal direction of the surface $z_{n}$ is the normal direction of the contact model, while $x_{t}$ and $y_{t}$ are the two tangential directions. 


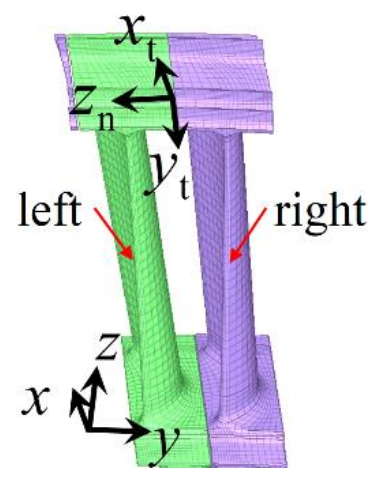

Figure 2. Local coordinate system of the shroud contact.

The 1D contact model assumes that the normal force is constant, and only one tangential relative motion at the contact surface is considered, as Figure 3. Based on 1D, the 2D contact model considers the change of normal force, as Figure 4. See [9] and Appendix A for 1D and Appendix B for 2D for the detailed contact law and the transition criteria of different contact states (stick, slip and separation).

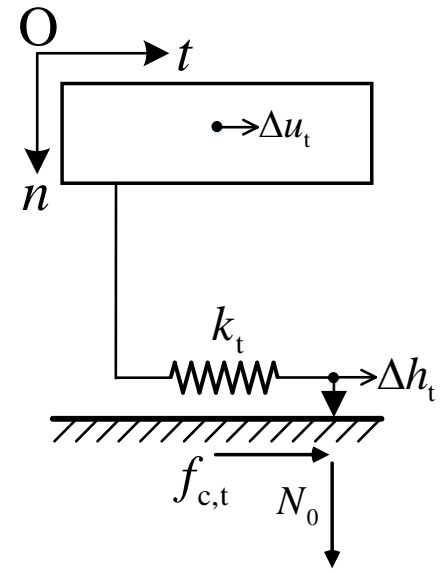

(a)

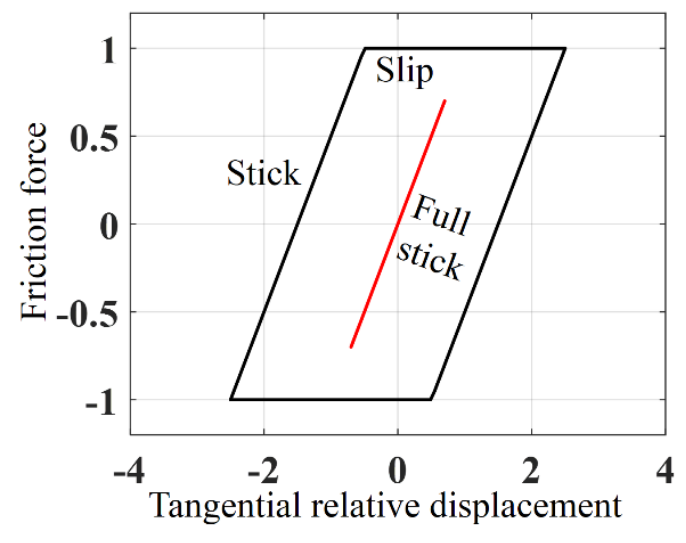

(b)

Figure 3. 1D Contact model: (a) 1D relative displacements and constant normal force; (b) Typical hysteresis loops.

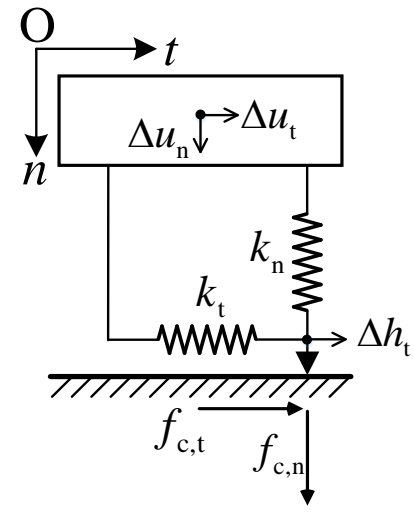

(a)

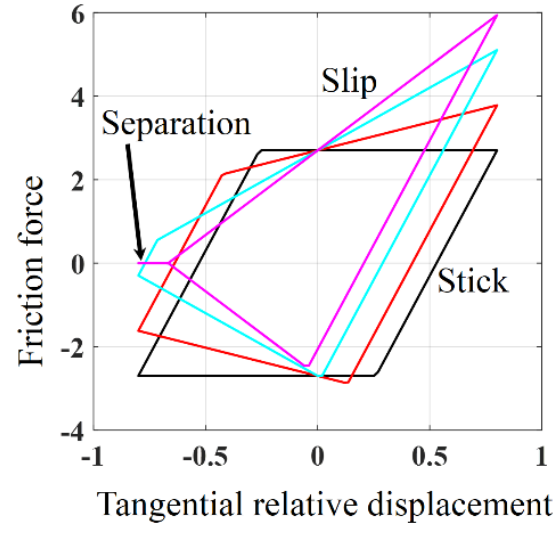

(b)

Figure 4. 2D Contact model: (a) 1D relative displacements and variable normal force; (b) Typical hysteresis loops. 


\subsection{Equivalent Stiffness of the Shroud Contact}

The contact has an effect on the damping and stiffness of the system. The equivalent stiffness between the contact surfaces of the blade shroud is needed to calculate the dynamic characteristics of the bladed disk system. There is a large gap between the adjacent pairs so their shrouds will not contact during vibration, while two shrouds in the same pair can contact and the contact pressure can be adjusted by interference fitting. The equivalent stiffness is calculated by nonlinear static analysis with contact. The cyclic symmetry interface and the contact surfaces including the shrouds, the blade tenon and disk mortise are as Figure 5.

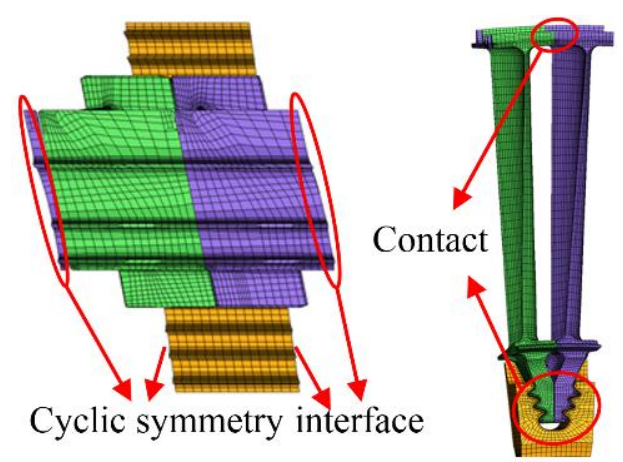

Figure 5. Local coordinate system of the shroud contact.

The nonlinear static analysis with the circumferential (y) and axial (z) displacement constraints in the global cylindrical coordinate system at some nodes of the disk, the slant constraints at the side of the blade tenon and the rotating speed to consider the compression effect of centrifugal force on the shroud. The equivalent stiffness of contact depends on the normal pressure and the shroud deformation in the analysis results.

The contact normal force $N_{0}$ first. Because the contact stress results of contact nonlinear static analysis depend on the mesh density and contact algorithm, the displacement results are relatively more robust. In order to obtain more accurate normal force, multiple linear static analyses are iteratively carried out by applying different pressure loads on the contact surface of the shroud until the displacement result is consistent with that of the contact nonlinear static analysis. The normal force on the whole surface at this time which is the product of pressure load and the area is the equivalent normal force $N_{0}$.

The deformation of the contact surface $\delta$ follows. Based on two static analyses with contact and without contact of the shrouds, the deformation of the shrouds under the two states is obtained. Taking the left shroud as an example, the deformed shape of the shroud in two states is drawn as Figure 6. The difference in normal deformation of the left shroud in contact with the free state is $\delta_{1}=\left|h_{\mathrm{fr}}-h_{\mathrm{co}}\right|$, similarly $\delta_{\mathrm{r}}$ for the right shroud-.

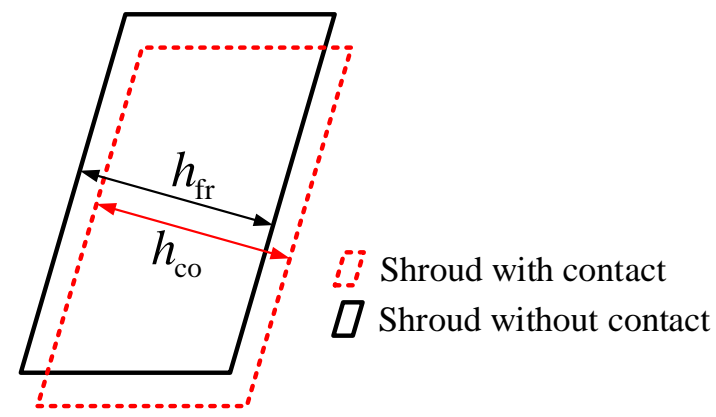

Figure 6. Schematic diagram of shroud deformation in two states.

The nonlinear static analysis with the circumferential (y) and axial (z) displacement constraints in the global cylindrical coordinate system at some nodes of the disk, the slant 
constraints at the side of the blade tenon and the rotating speed to consider the compression effect of centrifugal force on the shroud. The equivalent stiffness of contact depends on the normal pressure and the shroud deformation in the analysis results.

The equivalent normal contact stiffness is calculated by:

$$
k_{\mathrm{n}}=\frac{N_{0}}{\delta_{1}+\delta_{\mathrm{r}}}
$$

The tangential contact stiffness is obtained as follows: for the sphere-plate contact [27], the tangential and normal contact stiffness satisfies:

$$
k_{\mathrm{t}}=\lambda k_{\mathrm{n}}=\frac{2(1-v)}{2-v} k_{\mathrm{n}}
$$

where $v$ is Poisson's ratio. For the plate-plate contact in this paper, $\lambda$ is slightly smaller, and take $\lambda=1 / 3$. The results of the normal force and the contact stiffness are shown as Table 1 .

Table 1. Equivalent normal load and stiffness.

\begin{tabular}{ccc}
\hline $\begin{array}{c}\text { Normal Force } \\
N_{\mathbf{0}}(\mathbf{N})\end{array}$ & $\begin{array}{c}\text { Normal Contact Stiffness } \\
\boldsymbol{k}_{\mathrm{n}}\left(\times \mathbf{1 0}^{\mathbf{6}} \mathbf{N} / \mathbf{m}\right)\end{array}$ & $\begin{array}{c}\text { Tangential Contact Stiffness } \\
\boldsymbol{k}_{\mathrm{t}}\left(\times \mathbf{1 0}^{\mathbf{6}} \mathbf{N} / \mathbf{m}\right)\end{array}$ \\
\hline 7.145 & 2.06 & 0.69 \\
\hline
\end{tabular}

\section{Equivalent Damping Analysis}

\subsection{Calculation Method of Equivalent Damping Ratio}

The contact has an effect on the damping and stiffness of the system. The equivalent stiffness between the contact surfaces of the blade shroud is needed to calculate the dynamic characteristics of the bladed disk system. The mechanism of dry friction damping is that the friction generated by the relative motion between the contact surfaces dissipates the vibration energy. The ratio of dissipated energy to vibration energy can be used to evaluate the damping effect. The energy dissipated by friction in one vibration cycle can be obtained from the area enclosed by the hysteresis loop as:

$$
E_{\mathrm{f}}=\oint f_{c, t}(x) \mathrm{d} x
$$

Loss factor is often used to compare the damping effect of engineering materials [28], which can be expressed as the proportion of the dissipated energy of each vibration cycle to the vibration energy of the system, i.e.:

$$
\eta=\frac{E_{f}}{2 \pi E} \simeq 2 \zeta
$$

The vibration energy of the system can be approximated by the max vibration kinetic energy in a period, and the equivalent damping ratio provided by the shroud is approximately calculated by:

$$
\zeta=\frac{E_{f}}{4 \pi E_{k}}
$$

\subsection{Parameters for Damping Evaluation}

The matrix 27 elements are established between several pairs of nodes on the contact surface of the shroud, and their stiffness value are the contact stiffness, and the prestress modal analysis is carried out, which can be directly calculated with the help of commercial software, such as ANSYS ${ }^{\circledR}$. In the static analysis, the contact surface load is applied on the shroud contact surfaces, and the element stiffness of matrix 27 is set to 0 ; in the modal analysis, the surface load is deleted, and the stiffness of matrix 27 is set to the equivalent contact stiffness calculated above. 
The modes of interest are determined by Campbell. In this section, the equivalent damping ratios are calculated for three nodal diameters (ND), first bend (1B) mode and five ND first edgewise (1E) mode.

Designers hope that the shroud can play a significant damping role in resonance. The steady-state forced response of bladed disk remains periodic under EO traveling excitation. Assuming that the response is simple harmonic and traveling, the motion of shrouds can be expressed as:

$$
\begin{gathered}
\left\{\begin{array}{c}
u_{\mathrm{tl}}(t)=X_{\mathrm{tl}} \sin (\omega t) \\
u_{\mathrm{nl}}(t)=X_{\mathrm{nl}} \sin (\omega t)
\end{array}\right. \\
\left\{\begin{array}{c}
u_{\mathrm{tr}}(t)=X_{\mathrm{tr}} \sin \left(\omega t+\varphi_{\mathrm{k}}\right) \\
u_{\mathrm{nr}}(t)=X_{\mathrm{nr}} \sin \left(\omega t+\varphi_{\mathrm{k}}\right)
\end{array}\right.
\end{gathered}
$$

where the subscript $t$ means tangential, $n$ means normal, 1 represents left shroud, and $r$ represents right shroud. $\varphi_{\mathrm{k}}$ is Inter-Blade Phase Angle (IBPA), and $\omega$ is the natural angular frequency.

Using the full expansion of cyclic symmetry modal analysis, the sector with the largest amplitude is selected to extract the parameters needed for damping analysis. Parameters for damping evaluation are given in Table 2.

Table 2. Modal parameters for damping evaluation.

\begin{tabular}{ccc}
\hline Parameters & 3ND 1B & 5ND 1E \\
\hline Normal amplitude of the left shroud surface $X_{\mathrm{tl}} / \mathrm{mm}$ & 45.65 & 4.88 \\
Tangential amplitude of the left shroud surface $X_{\mathrm{nl}} / \mathrm{mm}$ & -1.00 & 45.41 \\
Normal amplitude of the right shroud surface $X_{\mathrm{tr}} / \mathrm{mm}$ & 45.56 & 4.90 \\
Tangential amplitude of the right shroud surface $X_{\mathrm{nr}} / \mathrm{mm}$ & 3.20 & 45.57 \\
Max vibration stress of blade $\sigma_{\mathrm{ref}} / \mathrm{MPa}$ & 5268 & 13,056 \\
Max vibration kinetic energy of the selected sector $E_{\mathrm{k}, \mathrm{ref}} / \mathrm{J}$ & 132 & 616 \\
$\mathrm{IBPA} \varphi_{\mathrm{k}} /{ }^{\circ}$ & 12 & 19 \\
\hline
\end{tabular}

where max vibration kinetic energy of the selected sector $E_{\mathrm{k}, \mathrm{ref}}$ is:

$$
E_{\mathrm{k}, \mathrm{ref}}=\frac{\max \left\{A_{i}^{2}, i=1,2, \ldots, 47\right\}}{\sum_{i=1}^{47} A_{i}^{2}} E_{\mathrm{k}, \mathrm{wh}}
$$

in which $E_{\mathrm{k} \text {,wh }}$ is the result of the full expansion. IBPA $\varphi_{\mathrm{k}}=2 \pi / N_{\mathrm{b}}$, where $k$ is ND number, and $N_{\mathrm{b}}$ is the number of blades.

In the contact model, the relative displacement of the shrouds is required as:

$$
\begin{aligned}
& \Delta u_{\mathrm{t}}(t)=u_{\mathrm{tr}}-u_{\mathrm{tl}}=\sqrt{X_{\mathrm{tl}}^{2}+X_{\mathrm{tr}}^{2}-2 X_{\mathrm{tl}} X_{\mathrm{tr}} \cos \left(\varphi_{\mathrm{k}}\right)} \sin \left(\omega t+\theta_{\mathrm{t}}\right)=A \sin \left(\omega t+\theta_{\mathrm{t}}\right) \\
& \Delta u_{\mathrm{n}}(t)=u_{\mathrm{nr}}-u_{\mathrm{nl}}=\sqrt{X_{\mathrm{nl}}^{2}+X_{\mathrm{nr}}^{2}-2 X_{\mathrm{nl}} X_{\mathrm{nr}} \cos \left(\varphi_{\mathrm{k}}\right)} \sin \left(\omega t+\theta_{\mathrm{t}}\right)=B \sin \left(\omega t+\theta_{\mathrm{n}}\right)
\end{aligned}
$$

1D contact model only needs tangential while in 2D model, not only the tangential and normal displacements but also the phase angle are needed. The relative displacements can be:

$$
\begin{aligned}
& \Delta u_{\mathrm{t}}(t)=A \sin (\omega t) \\
& \Delta u_{\mathrm{n}}(t)=B \sin (\omega t+\theta)
\end{aligned}
$$

where $A$ is the tangential amplitude, $B$ is the normal amplitude and $\theta=\theta_{\mathrm{n}}-\theta_{\mathrm{t}}$ is the phase angle between normal and tangential motion, as Table 3. 
Table 3. Modal parameters of relative motion for damping evaluation.

\begin{tabular}{ccc}
\hline Parameters & 3ND 1B & 5ND 1E \\
\hline Normal amplitude $A_{\text {ref }} / \mathrm{mm}$ & 9.13 & 1.63 \\
Tangential amplitude $B_{\text {ref }} / \mathrm{mm}$ & 4.19 & 15.13 \\
phase angle $\theta /^{\circ}$ & -92 & 0 \\
\hline
\end{tabular}

\subsection{Damping Characteristic Curve}

On a given mode, different amplitudes will correspond to different vibration stresses. Under small vibration amplitude conditions, the following relationships are satisfied between the modal and real vibration amplitude of relative motion, vibration stress, and max kinetic energy:

$$
\frac{X}{X_{\text {ref }}}=\frac{\sigma}{\sigma_{\text {ref }}}=\sqrt{\frac{E_{\mathrm{k}}}{E_{\mathrm{k}, \text { ref }}}}
$$

Firstly, the nonlinear static analysis is conducted to calculate the contact stiffness, which prepares for the subsequent modal analysis. Then, the modal parameters such as displacements, stress and energy are obtained by prestress modal analysis. Given the vibration stress $\sigma$, using equation and the parameters of (11), the tangential displacement $A$ and the max vibration kinetic energy $E_{\mathrm{k}}$ can be obtained; Then selecting the corresponding contact model, the corresponding friction energy dissipation $E_{\mathrm{f}}$ can be achieved, and then using (6) to calculate the equivalent damping ratio under the current vibration stress $\zeta$; By changing the vibration stress, the curve of damping ratio versus vibration stress can be acquired. The process of damping evaluation of shrouds under constant equivalent stiffness without considering the influence of shroud separation is shown as Figure 7.

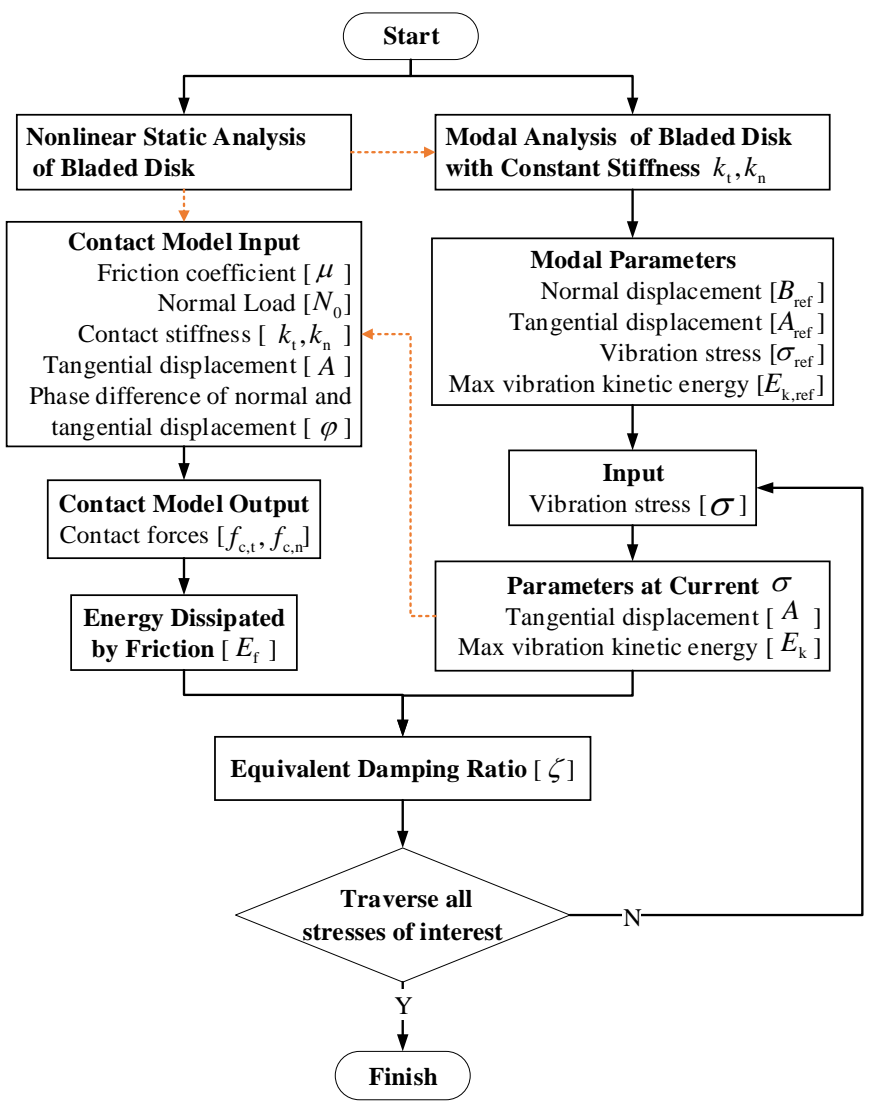

Figure 7. Flow chart of damping evaluation of shrouds with constant equivalent stiffness. 
Taking the friction coefficient $\mu=0.3$, the $1 \mathrm{D}$ and $2 \mathrm{D}$ contact models are used to calculate the damping curve for 3ND 1B and 5ND 1E modes, as seen in Figure 8.

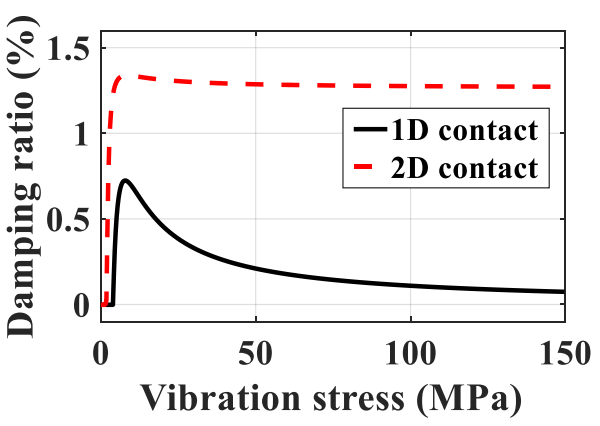

(a)

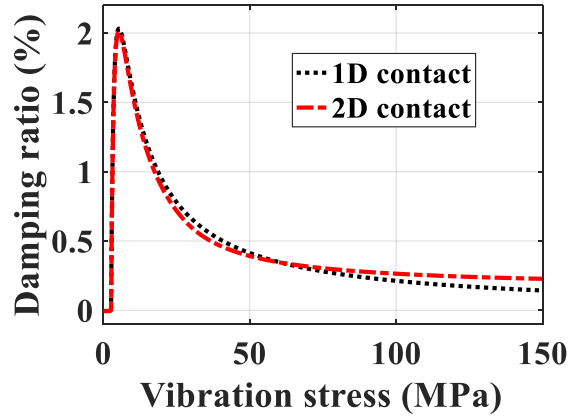

(b)

Figure 8. Damping curves of 1D and 2D contact for two modes: (a) 3ND 1B; (b) 5ND 1E.

Generally, under the same vibration stress, the damping ratio for $5 \mathrm{ND} 1 \mathrm{E}$ is larger than that for 3ND 1B, because the tangential displacement of the former is larger than that of the latter. It is worth noting the difference between 1D contact model and 2D contact model. The results for $3 \mathrm{ND} 1 \mathrm{~B}$ mode show that the damping ratio of $2 \mathrm{D}$ contact model is larger than that of $1 \mathrm{D}$, and the decreasing trend of damping ratio is not as obvious as that of 1D with the increase of vibration stress. The normal amplitude is several times larger than the tangential amplitude, and the separation will occur when the vibration stress is small. Although the separation will reduce the friction energy consumption, the max static friction also increases with the increase of vibration stress, resulting in more friction energy dissipation than 1D contact model. Figure 9 shows the contact hysteresis loop when the vibration stress is $10 \mathrm{MPa}$. The area enclosed by hysteresis loop (friction energy dissipation) of 2D contact model increases with the vibration stress approximately to the second power, while that of $1 \mathrm{D}$ contact model increases with the first power, which leads to that the change of equivalent damping ratio of $2 \mathrm{D}$ contact model with the vibration stress is not obvious.

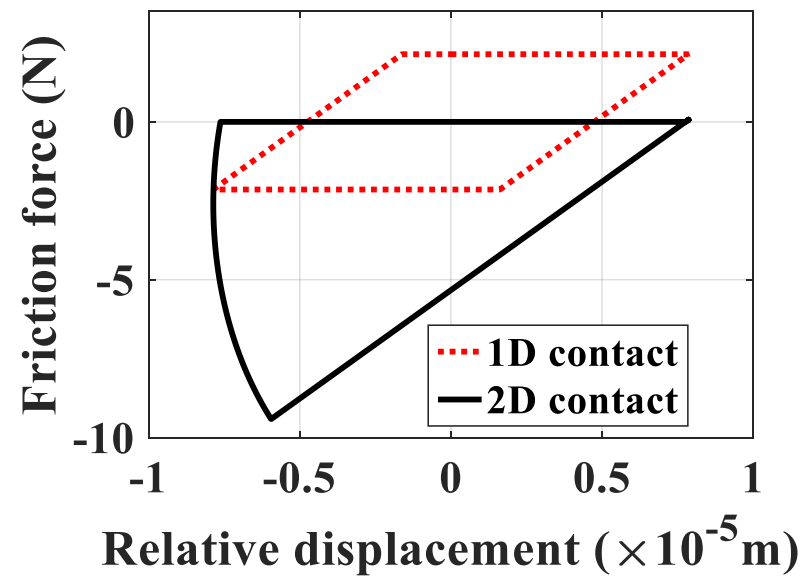

Figure 9. Hysteresis loop of two contact models for 3ND 1B mode under $\sigma=10 \mathrm{MPa}$.

However, for 5ND 1E mode, the normal displacement and the normal pressure of the contact surface change little, and the separation occurs only when the vibration stress is large enough. The friction energy dissipation between the two contact models is almost the same, so there is little difference in the damping characteristic curve, as Figure 10. 


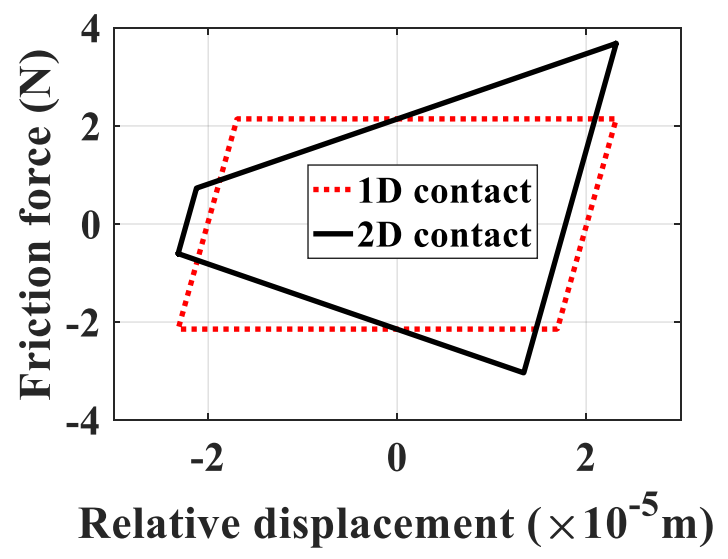

Figure 10. Hysteresis loop of two contact models for 5ND 1E mode under $\sigma=20 \mathrm{MPa}$.

\section{Damping-Evaluation with Altering Equivalent Stiffness}

It is easy to separate for the slant shrouds of blade pair, which causes the change of the equivalent stiffness of the contact surface. At this time, the condition of constant equivalent stiffness in the Section 3 is too strong. In this section, taking the 3ND 1B mode as an example, considering the change of equivalent stiffness caused by the separation state, the damping characteristics of the blade shroud are analyzed.

\subsection{Equivalent Stiffness on the Displacement Amplitude with the Separation}

The shroud surfaces of the blade pair may contact or separate. The equivalent stiffness is assumed to be the contact stiffness when contacting, and be zero when separating during vibration, as shown in Figure 11.

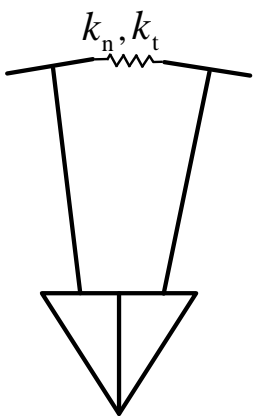

(a)

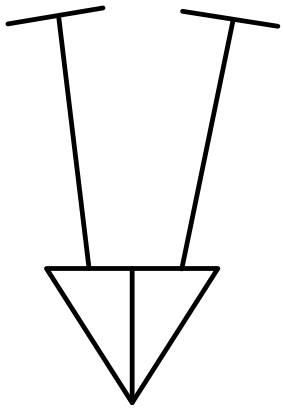

(b)

Figure 11. Schematic diagram of state of shrouds: (a) in contact; (b) in separation.

\subsubsection{Normal Force and Relative Motion}

If the shrouds do not separate during vibration, the normal relative displacement is $\Delta u_{\mathrm{n}}(\theta)=B \sin (\theta)$, and the normal force is $f_{\mathrm{c}, \mathrm{n}}(\theta)=N_{0}+k_{\mathrm{n}} B \sin (\theta)$. When the amplitude increases, leading to the separation of the shrouds, the normal force is zero, as follows:

$$
f_{\mathrm{c}, \mathrm{n}}(\theta)= \begin{cases}N_{0}+k_{\mathrm{n}} B \sin \theta, & 0<\theta \leq \theta_{1} \text { or } \theta_{2}<\theta \leq 2 \pi \\ 0, & \theta_{1}<\theta \leq \theta_{2}\end{cases}
$$

where $\theta_{1}=\pi-\arcsin \left(-N_{0} /\left(k_{\mathrm{n}} B\right)\right)$ and $\theta_{2}=2 \pi+\arcsin \left(-N_{0} /\left(k_{\mathrm{n}} B\right)\right)$ that are phase when separation, which can be calculated by $f_{\mathrm{c}, \mathrm{n}}(\theta)=0$. The Fourier expansion of the normal force only retains the constant and the first order term, which can be expressed as:

$$
\hat{f}_{\mathrm{c}, \mathrm{n}}(\theta)=F_{\mathrm{c}, \mathrm{n}}^{(0)}+F_{\mathrm{c}, \mathrm{n}}^{(1, \mathrm{c})} \cos \theta+F_{\mathrm{c}, \mathrm{n}}^{(1, \mathrm{~s})} \sin \theta
$$


in which:

$$
\begin{aligned}
F_{\mathrm{c}, \mathrm{n}}^{(0)} & =\frac{1}{2 \pi}\left[N_{0}\left(2 \pi-\theta_{2}+\theta_{1}\right)+k_{\mathrm{n}} B\left(\cos \theta_{2}-\cos \theta_{1}\right)\right], F_{\mathrm{c}, \mathrm{n}}^{(1, \mathrm{c})}=0 \\
F_{\mathrm{c}, \mathrm{n}}^{(1, \mathrm{~s})} & =\frac{1}{\pi}\left[N_{0}\left(\cos \theta_{2}-\cos \theta_{1}\right)+k_{\mathrm{n}} B\left(\pi-\frac{\theta_{2}-\theta_{1}}{2}-\frac{\sin 2 \theta_{1}-\sin 2 \theta_{2}}{4}\right)\right]
\end{aligned}
$$

The normal force and its Fourier series are shown as Figure 12.

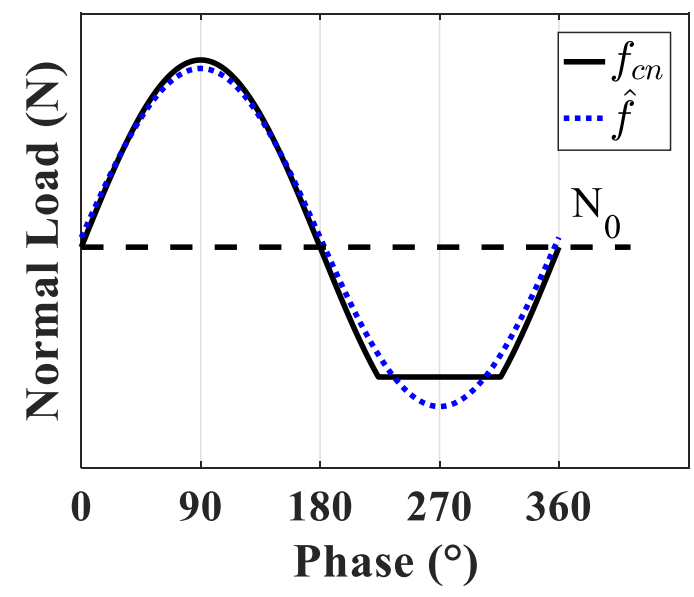

Figure 12. Normal force and its Fourier series.

Assuming that the normal amplitude with contact is $\gamma$ times of that without contact $(\gamma>1$, defined as amplitude factor), the normal displacement during one cycle (Figure 13) is:

$$
\Delta u_{\mathrm{n}}(\theta)= \begin{cases}B \sin \theta, & 0<\theta \leq \theta_{1} \text { or } \theta_{2}<\theta \leq 2 \pi \\ \gamma B \sin (\alpha \theta+\beta), & \theta_{1}<\theta \leq \theta_{2}\end{cases}
$$

where $\alpha=\left[\pi / 2+\arcsin \left(\sin \theta_{1} / \gamma\right)\right] /\left(1.5 \pi-\theta_{1}\right)$ and $\beta=1.5 \pi(1-\alpha)$.

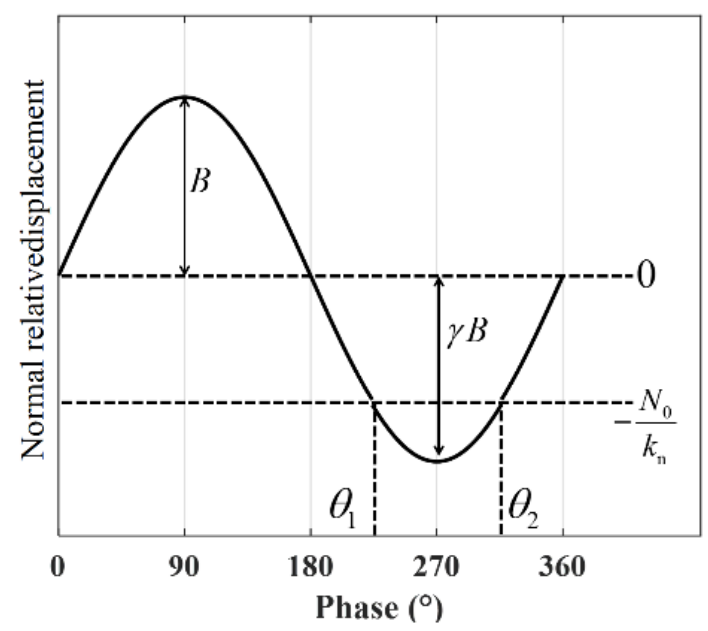

Figure 13. Normal relative displacement during one cycle.

The Fourier expansion of the normal relative displacement as Figure 14 can be:

$$
\Delta \hat{u}_{\mathrm{n}}(\theta)=\Delta U_{\mathrm{n}}^{(0)}+\Delta U_{\mathrm{n}}^{(1, \mathrm{c})} \cos \theta+\Delta U_{\mathrm{n}}^{(1, \mathrm{~s})} \sin \theta
$$

in which: 


$$
\begin{array}{ll}
\Delta U_{\mathrm{n}}^{(0)}= & \frac{1}{2 \pi}\left[\frac{\gamma B}{\alpha}\left(\cos \left(\alpha \theta_{1}+\beta\right)-\cos \left(\alpha \theta_{2}+\beta\right)\right)+B\left(\cos \theta_{2}-\cos \theta_{1}\right)\right], \Delta U_{\mathrm{c}, \mathrm{n}}^{(1, \mathrm{c})}=0 \\
\Delta U_{\mathrm{c}, \mathrm{n}}^{(1, \mathrm{~s})}= & \frac{1}{\pi}\left[B\left(\pi-\frac{\theta_{2}-\theta_{1}}{2}-\frac{\sin 2 \theta_{1}-\sin 2 \theta_{2}}{4}\right)\right. \\
& \left.+\frac{\gamma B}{2}\left(\frac{\sin \left(\alpha \theta_{2}-\theta_{2}+\beta\right)}{\alpha-1}-\frac{\sin \left(\alpha \theta_{2}+\theta_{2}+\beta\right)}{\alpha+1}-\frac{\sin \left(\alpha \theta_{1}-\theta_{1}+\beta\right)}{\alpha-1}+\frac{\sin \left(\alpha \theta_{1}+\theta_{1}+\beta\right)}{\alpha+1}\right)\right]
\end{array}
$$

in which, as an unknown quantity, $\gamma$ needs to be determined. It is noted that $\gamma$ depends on to the amplitude $\mathrm{B}$ of normal relative displacement.

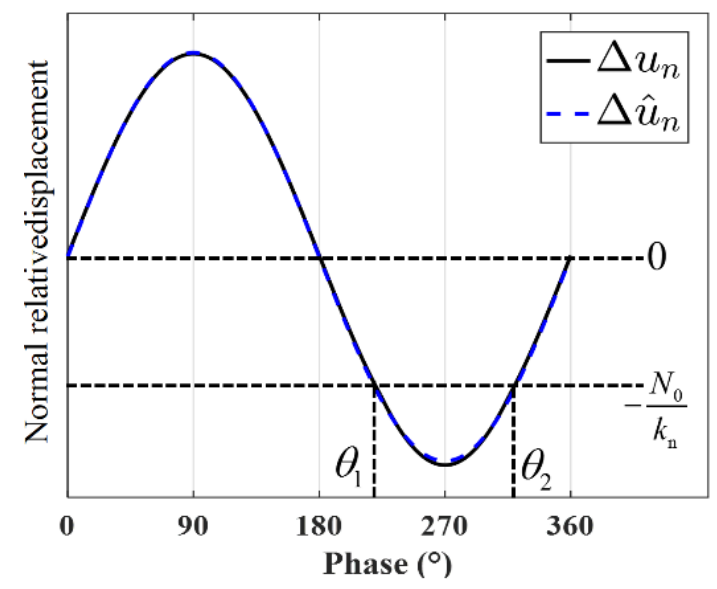

Figure 14. Normal relative displacement and its Fourier series.

\subsubsection{Amplitude Factor $\gamma$}

The amplitude factor of the separation and contact can be calculated by the lumped parameter EoM of the system:

$$
\begin{cases}M \ddot{u}+C_{\mathrm{c}} \dot{u}+\boldsymbol{K}_{\mathrm{c}} \boldsymbol{u}=f_{\mathrm{e}^{\prime}} & \text { contact } \\ \boldsymbol{M} \ddot{\boldsymbol{u}}+C_{\mathrm{s}} \dot{u}+\boldsymbol{K}_{\mathrm{s}} \boldsymbol{u}=f_{\mathrm{e}^{\prime}} & \text { separate }\end{cases}
$$

in which a circumferential harmonic excitation force is applied to the node at the position of $2 / 3$ blade height and $1 / 2$ chord length. The subscript $c$ means shrouds in the contact state while s means in the separation state.

By the mass-normalized modes in two states for 3ND 1B $\varphi_{\mathrm{c}}$ and $\varphi_{\mathrm{s}}$, and further normalize them to $\varphi_{\mathrm{c}} / \varphi_{\mathrm{cb}}$ and $\varphi_{\mathrm{s}} / \varphi_{\mathrm{sb}}$, where $\varphi_{\mathrm{cb}}$ and $\varphi_{\mathrm{sb}}$ represent the amplitude of relative displacement from $\varphi_{\mathrm{c}}$ and $\varphi_{\mathrm{s}}$. The EoM is transformed into the modal space by $\boldsymbol{u}=$ $\left(\varphi_{\mathrm{c}} / \varphi_{\mathrm{cb}}\right) q$ and $\boldsymbol{u}=\left(\varphi_{\mathrm{s}} / \varphi_{\mathrm{sb}}\right) q$, so as to obtain the EoM expressed by the modal coordinates:

$$
\begin{cases}m_{\mathrm{c}} \ddot{q}+c_{\mathrm{c}} \dot{q}+k_{\mathrm{c}} q=f_{\mathrm{e}, \mathrm{c}} \cos \theta, & q<N_{0} / k_{\mathrm{n}} \\ m_{\mathrm{s}} \ddot{q}+k_{\mathrm{s}} q=f_{\mathrm{e}, \mathrm{s}} \cos \theta, & q \geq N_{0} / k_{\mathrm{n}}\end{cases}
$$

where $m, c$ and $k$ are modal mass, damping coefficient and stiffness, $f_{\mathrm{e}}$ means the modal excitation. $m_{\mathrm{c}} / m_{\mathrm{s}}=\left(\varphi_{\mathrm{sb}} / \varphi_{\mathrm{cb}}\right)^{2}, k_{\mathrm{c}} / k_{\mathrm{s}}=m_{\mathrm{c}} / m_{\mathrm{s}}\left(\omega_{\mathrm{c}} / \omega_{\mathrm{s}}\right)^{2}$ in which $\omega_{\mathrm{c}}$ and $\omega_{\mathrm{s}}$ are the natural angular frequencies for 3ND 1B modes in two states, respectively. $f_{\mathrm{e}, \mathrm{c}} / f_{\mathrm{e}, \mathrm{s}}=\varphi_{\mathrm{cf}} \varphi_{\mathrm{sb}} /\left(\varphi_{\mathrm{sf}} \varphi_{\mathrm{cb}}\right)$ where $\varphi_{\mathrm{cf}}$ and $\varphi_{\mathrm{cb}}$ are the modal displacements at excited position. The EoM is dimensionless as:

$$
\begin{cases}\ddot{\bar{q}}(\bar{\omega} t)+2 \zeta(\bar{B}) \dot{\bar{q}}(\bar{\omega} t)+\bar{q}(\bar{\omega} t)=\bar{f}_{\mathrm{e}, \mathrm{c}} \cos (\bar{\omega} t), & \bar{q}<1 \\ \frac{m_{\mathrm{s}}}{m_{\mathrm{c}}} \overline{\bar{q}}(\bar{\omega} t)+\frac{k_{\mathrm{s}}}{k_{\mathrm{c}}} \bar{q}(\bar{\omega} t)=\bar{f}_{\mathrm{e}, \mathrm{s}} \cos (\bar{\omega} t), & \bar{q} \geq 1\end{cases}
$$

where $\bar{q}=q / B_{0}, \bar{\omega}=\omega / \omega_{\mathrm{c}}, \bar{f}_{\mathrm{e}, \mathrm{c}}=f_{\mathrm{e}, \mathrm{c}} /\left(m_{\mathrm{c}} \omega_{\mathrm{c}}^{2} B_{0}\right), \bar{f}_{\mathrm{e}, \mathrm{s}}=f_{\mathrm{e}, \mathrm{s}} /\left(m_{\mathrm{c}} \omega_{\mathrm{c}}^{2} B_{0}\right), B_{0}=N_{0} / k_{\mathrm{n}}$ is defined as the critical amplitude of separation, and $\bar{B}=B / B_{0} \cdot \zeta(\bar{B})$ is damping ratio calculated above with the constant equivalent stiffness (red dashed line in Figure 8). The Newmark method can be used to solve the dimensionless lumped-parameter EoM: 
(1) For each amplitude and frequency of excitation, the corresponding displacement-time curve can be calculated. It should be noted that since $\zeta$ is related to the unknown $\bar{B}$, an iterative solution between is needed;

(2) By changing the excitation frequency, the max response amplitude and its corresponding frequency can be obtained, which are respectively resonance amplitude and resonance frequency; the amplitude of separation and contact in a period of resonance can be extracted, and the amplitude factor $\gamma$ under the current resonance amplitude can be calculated;

(3) Change the excitation amplitude to obtain amplitude factor. Figure 15 shows the curve of amplitude factor $\gamma$ with the dimensionless normal amplitude $\bar{B}$.

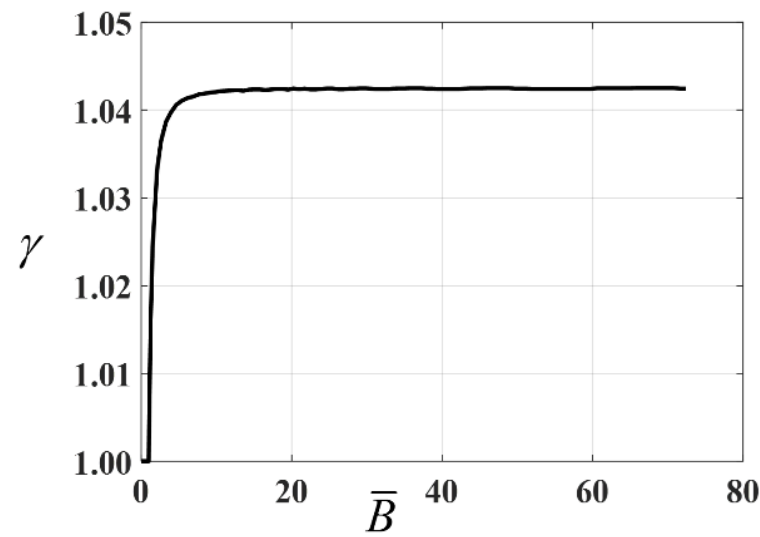

Figure 15. Amplitude factor $\gamma$ on the dimensionless normal amplitude $\bar{B}$.

\subsubsection{Equivalent Stiffness on Amplitude}

Given $B$, the corresponding $\gamma$ extracted from Figure 15, Fourier coefficients of normal displacement from (14) and (17), the equivalent normal and tangential stiffness can be calculated by:

$$
\left\{\begin{array}{l}
k_{\mathrm{n}}^{\mathrm{eq}}=F_{\mathrm{c}, \mathrm{n}}^{(1, \mathrm{~s})} / \Delta U_{\mathrm{n}}^{(1, \mathrm{~s})} \\
k_{\mathrm{t}}^{\mathrm{eq}}=k_{\mathrm{t}} k_{\mathrm{n}}^{\mathrm{eq}} / k_{\mathrm{n}}
\end{array}\right.
$$

Define the dimensionless normal stiffness as $\bar{k}_{\mathrm{n}}^{\mathrm{eq}}=k_{\mathrm{n}}^{\mathrm{eq}} / k_{\mathrm{n}}$, and the curve of $\bar{k}_{\mathrm{n}}^{\mathrm{eq}}$ on $\bar{B}$ is shown as Figure 16 . With the increase of $\bar{B}, \bar{k}_{\mathrm{n}}^{\mathrm{eq}}$ will decrease gradually until it is half of the original. This is because the ratio of the separation time to the whole vibration period is gradually approaching 0.5 .

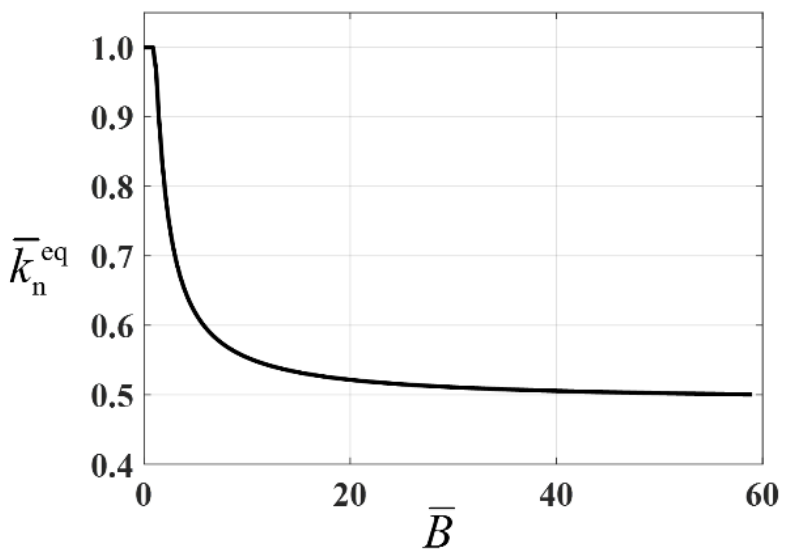

Figure 16. Equivalent normal stiffness $\bar{k}_{\mathrm{n}}^{\mathrm{eq}}$ on the dimensionless normal amplitude $\bar{B}$. 


\subsection{Parameters for Damping Evaluation}

According to Figure 16, given the normal relative amplitude, the corresponding equivalent normal and tangential stiffness can be calculated. Then, the parameters required for damping can be achieved following the method in Section 3.2. The difference is that the equivalent stiffness in this section changes with the amplitude. For every normal amplitude, a modal analysis is needed, which takes a long time. This paper selects several modes of a single blade to fit the modes of bladed disk with different equivalent stiffness, so as to simplify the computation.

Nine modes of the single left blade $\psi_{j}, j=1, \ldots, N_{\mathrm{r}}(1 \mathrm{~B}, 1 \mathrm{E}$, first torsion (1T), 2B, 3B, $4 \mathrm{~B}$, rigid body rotating around $\mathrm{z}$-axis, translating along $\mathrm{x}$-axis and translating along $\mathrm{y}$-axis) normalized by amplitude to form the reduction basis $\boldsymbol{\Psi}$ and the right blade is similar. The columns in $\Psi$ are the selected modes which are linearly independent. The 3ND 1B mode $\varphi\left(k_{\mathrm{n}}^{\mathrm{eq}}\right)$ of the bladed disk is still selected as the target mode to be fitted. Noting that $\varphi\left(k_{\mathrm{n}}^{\mathrm{eq}}\right)$ varies with equivalent stiffness, several typical equivalent stiffness values are selected for modal analysis, and the corresponding 3ND 1B modes $\varphi\left(k_{\mathrm{n}}^{\mathrm{eq}}\right)$ are obtained. The 3ND $1 \mathrm{~B}$ under three cases of 1, 0.5, 0 times stiffness calculated in Section 2.3. Tables 4 and 5 respectively list the coefficients $\chi_{j}$ and errors $\varepsilon$ of the selected reduced basis vectors of the left and right blades when fitting the 3ND 1B mode of the bladed disk under the above typical equivalent stiffness values.

Table 4. Fitting coefficient of reduced modes of left blade.

\begin{tabular}{cccc}
\hline Single Blade & \multicolumn{3}{c}{$\chi_{j}$ of Different Stiffness } \\
\cline { 2 - 4 } Reduction Basis $\psi_{j}$ & $\boldsymbol{\varphi ( 0 )}$ & $\boldsymbol{\varphi ( 0 . 5 )}$ & $\boldsymbol{\varphi ( \mathbf { ) } )}$ \\
\hline 1B & -0.56 & -0.54 & -0.53 \\
1E & 0.07 & 0.07 & 0.07 \\
1T & 0.03 & 0.04 & 0.04 \\
2B & -0.02 & -0.03 & -0.04 \\
3B & 0.00 & 0.00 & 0.01 \\
4B & 0.00 & -0.01 & -0.01 \\
RB Rotating z & -1.15 & -1.25 & -1.31 \\
RB Translating x & 0.69 & 0.75 & 0.78 \\
RB Translating y & 0.01 & 0.01 & 0.02 \\
error $\varepsilon$ & $0.00537 \%$ & $0.00585 \%$ & $0.00656 \%$ \\
\hline
\end{tabular}

Table 5. Fitting coefficient of reduced modes of right blade.

\begin{tabular}{cccc}
\hline Single Blade & \multicolumn{3}{c}{$\boldsymbol{\chi}_{j}$ of Different Stiffness } \\
\cline { 2 - 4 } Reduction Basis $\boldsymbol{\psi}_{j}$ & $\boldsymbol{\varphi ( \mathbf { 0 } )}$ & $\boldsymbol{\varphi ( \mathbf { 0 . 5 } )}$ & $\boldsymbol{\varphi ( \mathbf { 1 } )}$ \\
\hline 1B & 0.55 & 0.54 & 0.53 \\
1E & 0.07 & 0.08 & 0.08 \\
1T & 0.03 & 0.04 & 0.05 \\
2B & 0.02 & 0.03 & 0.04 \\
3B & 0.00 & 0.00 & -0.01 \\
4B & 0.00 & 0.01 & 0.01 \\
RB Rotating z & -1.18 & -1.26 & -1.32 \\
RB Translating x & 0.70 & 0.75 & 0.79 \\
RB Translating y & 0.05 & 0.05 & 0.05 \\
error $\varepsilon$ & $0.00507 \%$ & $0.00557 \%$ & $0.00616 \%$ \\
\hline
\end{tabular}

where $\chi_{j}$ and $\varepsilon$ [29] can be expressed as:

$$
\chi_{j}=\frac{\varphi^{T}\left(k_{\mathrm{n}}^{\mathrm{eq}}\right) \boldsymbol{\psi}_{j}}{\left\|\boldsymbol{\varphi}\left(k_{\mathrm{n}}^{\mathrm{eq}}\right)\right\|\left\|\boldsymbol{\psi}_{j}\right\|}
$$


The approximate mode after fitting is:

$$
\tilde{\varphi}=\sum_{j}^{N_{r}} \chi_{j} \psi_{j}
$$

and $\varepsilon=\|\varphi-\tilde{\varphi}\| /\|\varphi\|$.

For other equivalent stiffness values $k_{\mathrm{n}}^{\mathrm{eq}}$, the fitting coefficients $\chi_{j}^{k_{\mathrm{n}}^{\mathrm{eq}}}$ of each reduced mode are obtained by linear interpolation of data in Tables 4 and 5 as:

$$
\frac{\chi_{j}^{k_{\mathrm{n}}^{\mathrm{eq}}}-\chi_{j}^{0.5}}{k_{\mathrm{n}}^{\mathrm{eq}} / k_{\mathrm{n}}-0.5}=\frac{\chi_{j}^{1.0}-\chi_{j}^{0.5}}{1.0-0.5}
$$

Thus, the calculation steps of modal parameters for equivalent damping can be summarized as:

(1) Extract the following modal data from each mode $\boldsymbol{\psi}_{j}$ in reduction basis $\Psi$ : the displacements in three directions $\left(X_{c, x, j}^{\mathrm{ro}}, X_{c, y, j}^{\mathrm{ro}}, X_{\mathrm{c}, \mathrm{z}, j}^{\mathrm{ro}}\right)^{\mathrm{T}}$, the vibration stress at critical location $\sigma_{j}^{\mathrm{ro}}$, the max kinetic energy $E_{\mathrm{k}, j}^{\mathrm{ro}}$;

(2) Given the amplitude B, the new equivalent stiffness $k_{\mathrm{n}}^{\mathrm{eq}}=F_{\mathrm{c}, \mathrm{n}}^{(1, \mathrm{~s})} / \Delta U_{\mathrm{n}}^{(1, \mathrm{~s})}$ and the fitting coefficients of the reduced modes under the current stiffness $\chi_{j}^{k_{n}^{e q}}$ are obtained;

(3) Combined with Section 3.2, the displacements in three directions under this equivalent stiffness can be obtained by $X_{\mathrm{c}, \mathrm{x}}^{k_{\mathrm{n}}^{\mathrm{eq}}}=\sum_{j=1}^{N_{\mathrm{r}}} \chi_{j}^{k_{\mathrm{n}}^{\mathrm{eq}}} X_{\mathrm{c}, x, j^{\prime}}^{\mathrm{ro}}$ for $X_{\mathrm{c}, y}^{k_{\mathrm{n}}^{\mathrm{eq}}}$ and $X_{\mathrm{c}, \mathrm{z}}^{k_{\mathrm{n}}^{\mathrm{eq}}}$ in the same way; The relative amplitudes $A_{\text {ref }}$ and $B_{\text {ref }}$ in the local coordinate system are calculated; Vibration stress vector under this stiffness is $\sigma^{k_{\mathrm{n}}^{\mathrm{eq}}}=\sum_{j=1}^{N_{\mathrm{r}}} \chi_{j}^{k_{\mathrm{n}}^{\mathrm{eq}}} \sigma_{j}^{\mathrm{ro}}$, in which the max component is taken as $\sigma_{\text {ref; }}$ The max vibration kinetic energy is $\sigma_{\mathrm{k}, \mathrm{ref}}=\sum_{j=1}^{N_{\mathrm{r}}} \chi_{j}^{k_{\mathrm{n}}^{\mathrm{eq}}} E_{\mathrm{k}, j}^{\mathrm{ro}}$.

\subsection{Damping Characteristic Curve with the Altering Stiffness}

Given normal amplitude $B$, the real and modal parameters: normal and tangential displacement, stress and kinetic energy satisfy:

$$
\frac{\sigma}{\sigma_{\text {ref }}}=\frac{B}{B_{\text {ref }}}=\frac{A}{A_{\text {ref }}}=\frac{\sqrt{E_{k}}}{\sqrt{E_{k, \text { ref }}}}
$$

Combined with the modal parameters calculated in Section 4.2, the corresponding friction energy consumption can be obtained by selecting the corresponding contact model, and then the equivalent damping ratio under different vibration stress can be calculated by Equation (6), as shown in Figure 17, where the upper right part is to calculate the change of equivalent stiffness with the amplitude of normal motion, and the lower right part is the step to fit the vibration mode. These two parts provide the necessary parameters for the calculation of equivalent damping with altering stiffness, which need to be conducted in advance. Given the vibration stress $B$, using equation and the parameters of (26), the tangential displacement $A$ and the max vibration kinetic energy $E_{\mathrm{k}}$ can be obtained; Then using the 2D contact model, the corresponding friction energy dissipation $E_{\mathrm{f}}$ can be achieved, and then using (6) to calculate the equivalent damping ratio under the current vibration stress $\zeta$. 


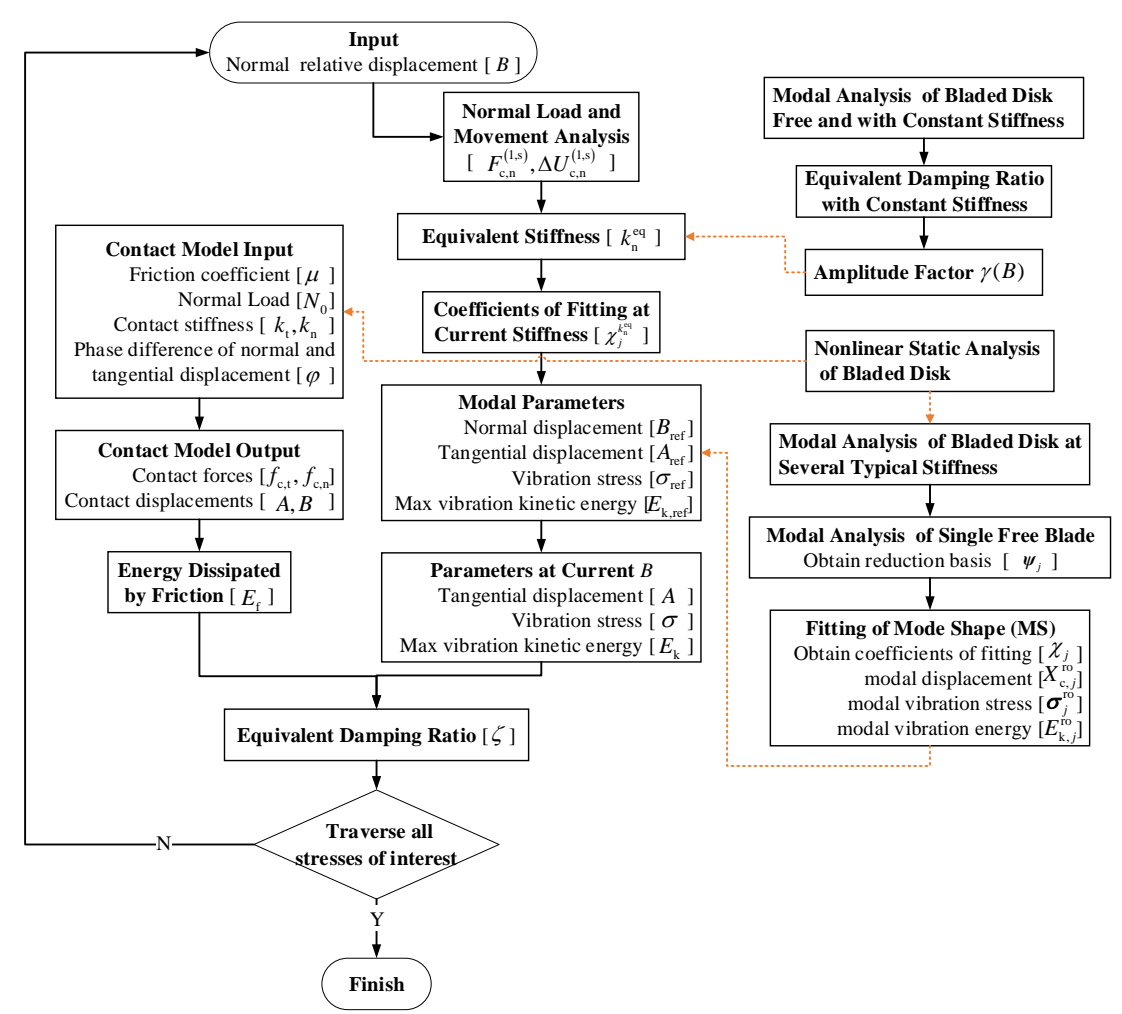

Figure 17. Flow chart of damping evaluation of shrouds with altering equivalent stiffness.

For the shrouded bladed disk in this paper, Figure 18 shows the damping characteristic curves obtained by three methods. The damping ratio of 2D contact model with altering stiffness method is lower than that with constant stiffness method, but it is still higher than that of $1 \mathrm{D}$ contact model. It is worth noting that the calculation time of a damping characteristic curve is very short, which is very suitable for engineering applications. The calculation time of three methods that are 1D and 2D contact model with constant stiffness and $2 \mathrm{D}$ with altering stiffness for 3ND $1 \mathrm{~B}$ under the conditions of a normal PC configuration (Intel ${ }^{\circledR}$ Core $^{\mathrm{TM}}$ i7-6700 CPU @ $3.40 \mathrm{GHz}$, RAM 16.0 GB) is $0.21,0.08$ and 1.15, respectively.

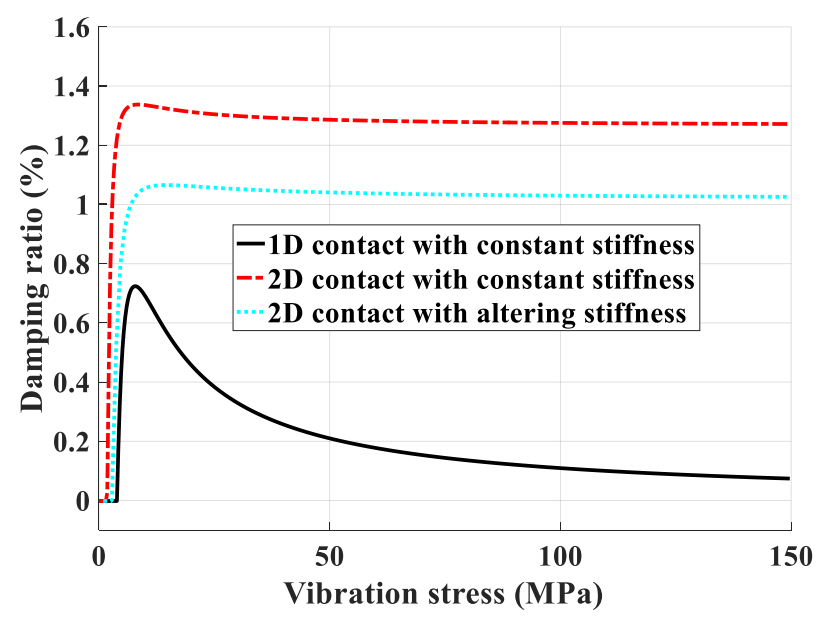

Figure 18. Damping curves with three methods for 3ND 1B mode.

\section{Discussion}

\subsection{Vibration-Reduction Design}

The mechanism of dry friction damping is that the friction generated by the relative motion between the contact surfaces dissipates the vibration kinetic energy. From the 
perspective of energy, the ratio of friction dissipation to the max vibration kinetic energy of the system can be used to evaluate the damping effect. In this paper, the damping characteristic curve is used to study the vibration reduction, which is the curve of the damping ratio provided by the system with the vibration stress, as shown in Figure 19. The important parameters are: the critical vibration stress $\sigma_{\mathrm{cr}}$ which is the resonance vibration stress at critical location, the peak damping ratio $\zeta_{\max }$ and the corresponding vibration stress $\sigma_{\mathrm{m}}$. During the design phase, the objective is to increase the peak damping ratio as much as possible under the allowable vibration stress; at the same time, the critical vibration stress should be relatively small; in addition, the typical vibration stress of the blade should preferably fall in the left half of the damping characteristic curve, so that when the vibration stress increases, the damping ratio provided by the shroud will also increase.

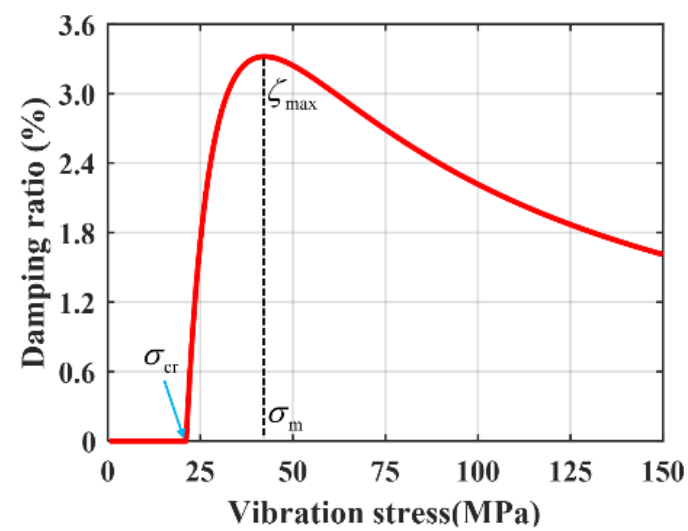

Figure 19. Schematic diagram of damping characteristic curve.

The flow chart of vibration reduction design based on the damping characteristics of the blade shroud is shown in Figure 20, where $\sigma_{\mathrm{a}}$ is the allowable vibration stress of the system, which is often located in the blade body.

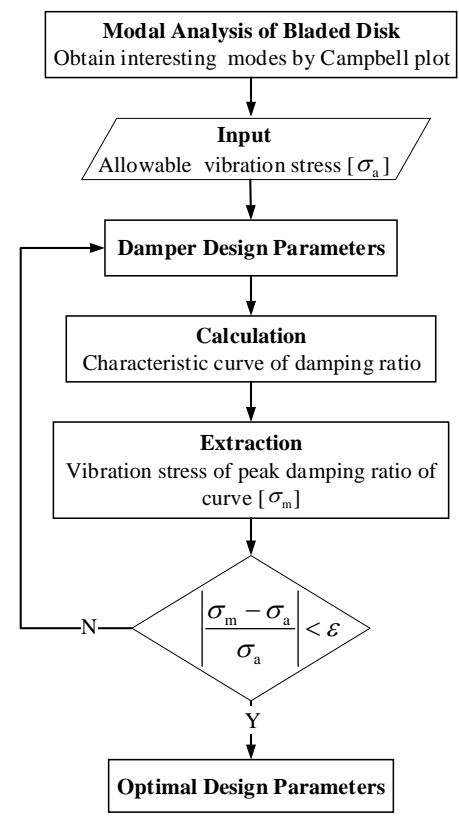

Figure 20. Flow chart of vibration reduction design of shrouds. 


\subsection{Sensitivity Analysis}

The parameter sensitivity analysis of the damping curve for the 3ND $1 \mathrm{~B}$ of the bladed disk is carried out that are phase angle between normal and tangential motion, the contact stiffness, friction coefficient and initial normal force.

\subsubsection{Phase Angle between Normal and Tangential Motion}

When the 2D contact model is used, the phase angle will greatly affect the hysteresis loop, and then the energy dissipation, thus influencing the damping characteristic curve. Figure 21 shows the damping characteristic curves when the phase angle is from $0^{\circ}$ to $90^{\circ}$. The phase angle of black solid line is $90^{\circ}$ and that of red solid line is $0^{\circ}$ in the two figures.

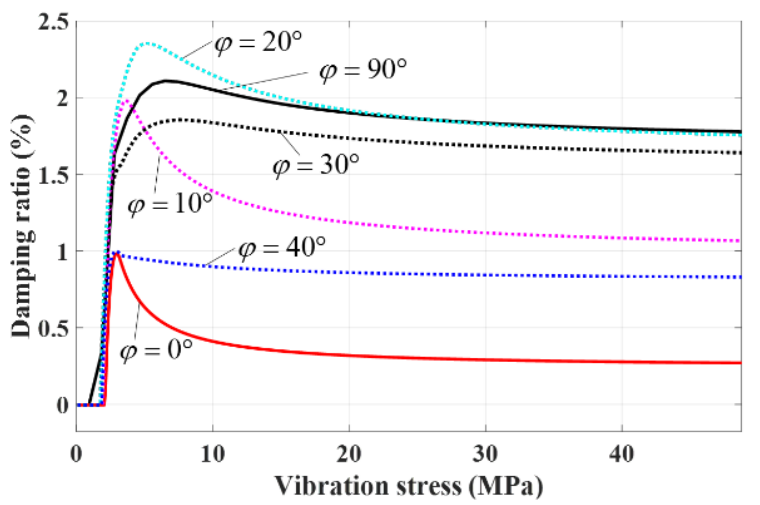

(a)

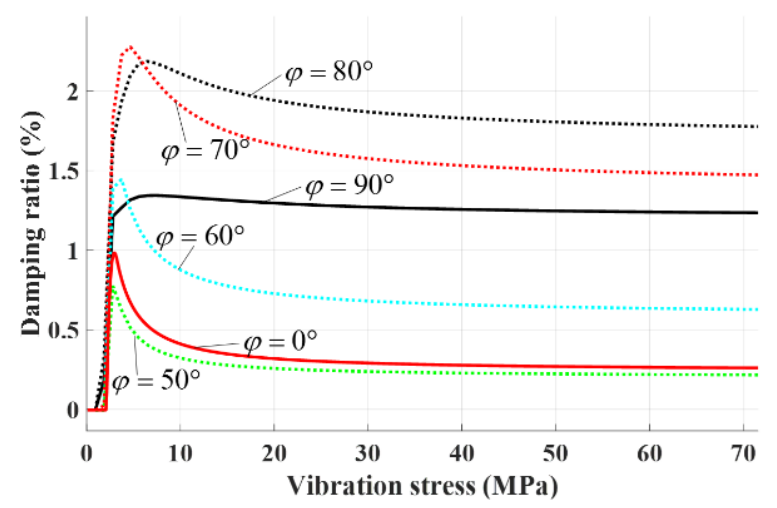

(b)

Figure 21. Damping curves with variation of phase angles: (a) $0^{\circ}-40^{\circ}$; (b) $50^{\circ}-90^{\circ}$.

\subsubsection{Contact Stiffness}

In the contact model, the contact stiffness is an important parameter, but difficult to determine. Its value directly affects the friction energy dissipation and vibration response. It is related to the contact surface pressure, geometry, friction coefficient, temperature and surface roughness. At present, there is no reliable and unified numerical calculation method [30], and it is usually obtained by experimental measurement as input parameters for simulating. Therefore, its value often come with variable degrees of uncertainty. Figure 22 shows the sensitivity of the damping curve to variations in the contact stiffness. 2D contact model, phase angle and normal force in Table 1 are used herein. The stiffness values in this figure are given in the form of $\left(k_{\mathrm{t}}, k_{\mathrm{n}}\right)$ in which $k_{0}=2.06 \times 10^{6} \mathrm{~N} / \mathrm{m}$. The black color indicates $k_{\mathrm{t}}=k_{\mathrm{n}}$ : when the contact stiffness decreases from $4 k_{0}$ to $k_{0}, \zeta_{\max }$ decreases from $3.4 \%$ to $0.5 \%$, and $\sigma_{\mathrm{cr}}$ increases from $0.93 \mathrm{MPa}$ to $7.13 \mathrm{MPa}$; With $k_{\mathrm{t}}=k_{\mathrm{n}}=4 k_{0}$, when $\sigma>\sigma_{\mathrm{m}}$, the equivalent damping ratio decreases obviously with the increase of vibration stress. The multicolor indicates $k_{\mathrm{t}} \neq k_{\mathrm{n}}$ : when the contact stiffness varies from $k_{\mathrm{t}}=k_{\mathrm{n}} / 2$ to $k_{\mathrm{t}}=k_{\mathrm{n}} / 4, \zeta_{\max }$ decreases from $1.45 \%$ to $0.83 \%$, and $\sigma_{\mathrm{cr}}$ increases from $2.61 \mathrm{MPa}$ to $3.07 \mathrm{MPa}$. 


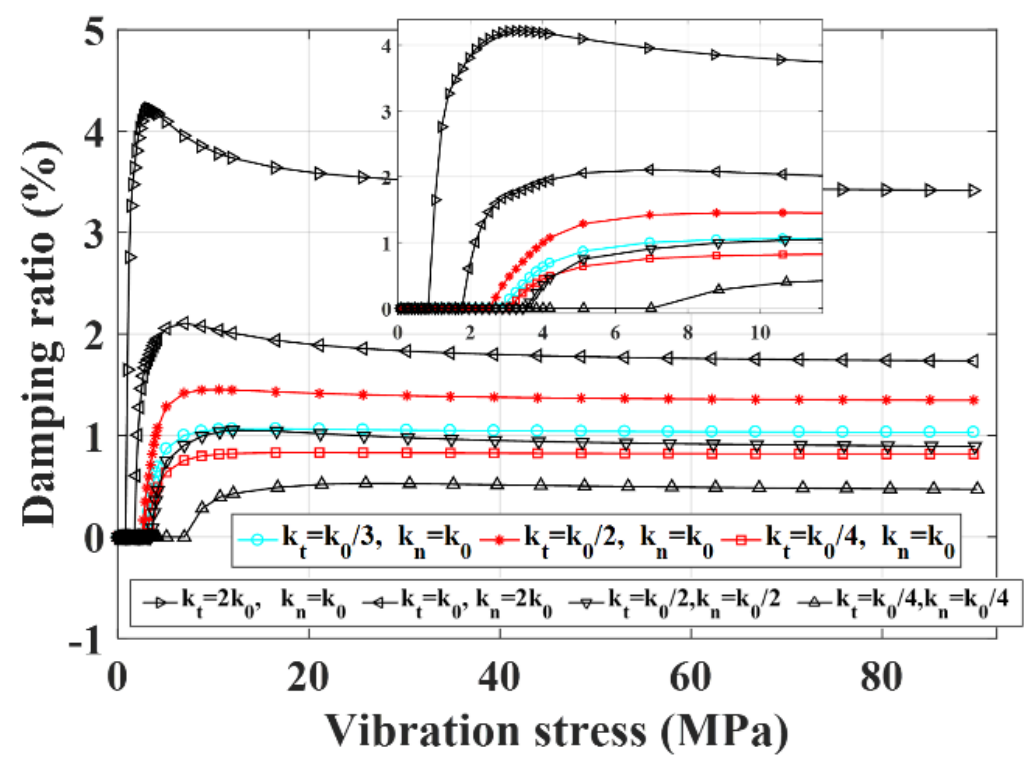

Figure 22. Damping curves with variation of contact stiffness.

\subsubsection{Initial Contact Normal Force}

The initial normal force is a design parameter, which is related to the interference between the shrouds and the rotating speed. The amplitude first decreases and then increases with the increase of normal force, so there is an optimal value to minimize the amplitude [30,31]. Figure 23 shows the effect of the normal force on the damping curves. 2D contact model, phase angle and contact stiffness in Table 1 are used herein. When the initial normal force increases, the sliding difficulty of sliding increases, and the critical vibration stress increases. However, the peak damping ratio remains basically unchanged, but its corresponding vibration stress increases.

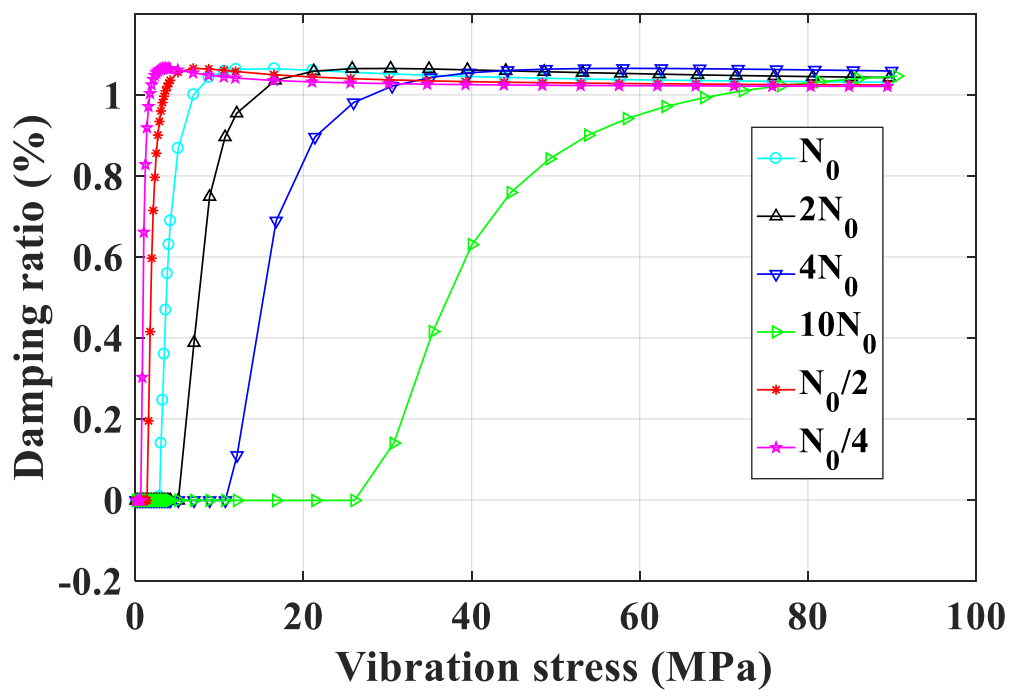

Figure 23. Damping curves with variation of normal force.

\subsubsection{Friction Coefficient}

With the increase of blade working time, the contact surface of shroud will become smooth gradually, resulting in the change of friction coefficient. Take the friction coefficient $\mu=0.1,0.2,0.3,0.4,0.5$ to study its influence on the damping curves as in Figure 24. Initial normal force and contact stiffness in Table 1 are used herein. The critical vibration stress increases with the friction coefficient due to the increase of the Coulomb limit, which makes the contact surface more difficult to slip. The peak damping ratio also grows with the 
friction coefficient, which is due to the increase of friction force and energy dissipation. Both the critical vibration stress and peak damping ratio first increase and then stabilize with the friction coefficient as in Figure 25.

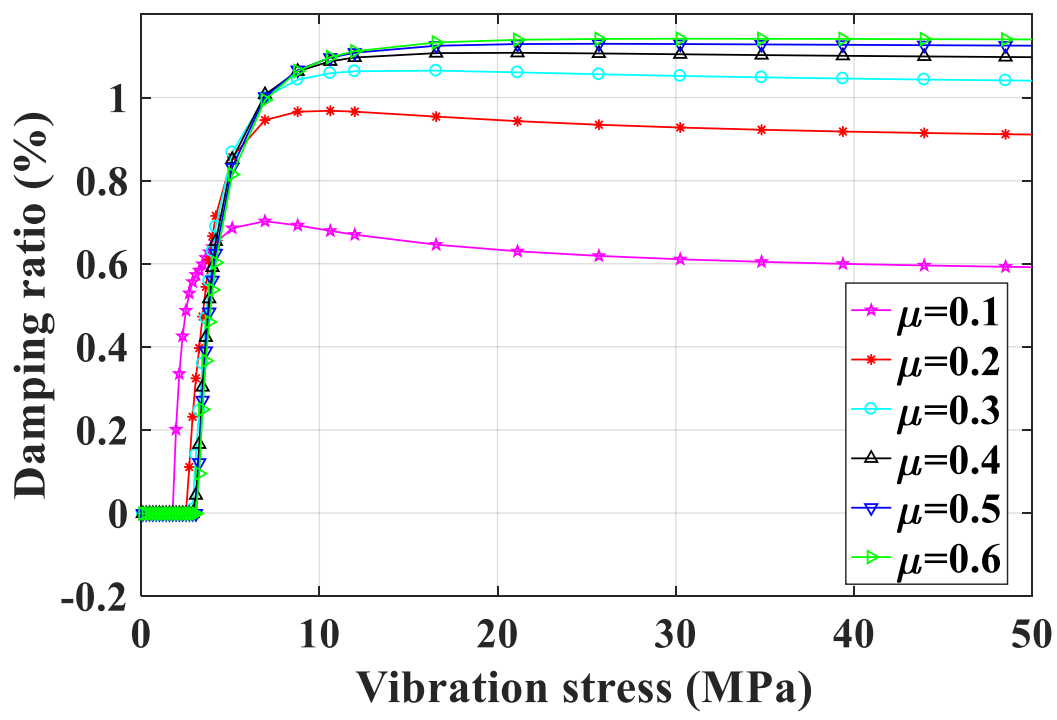

Figure 24. Damping curves with variation of friction coefficient.

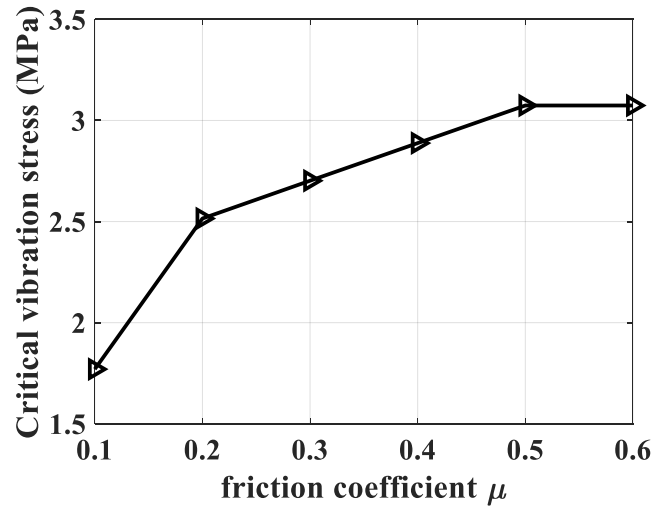

(a)

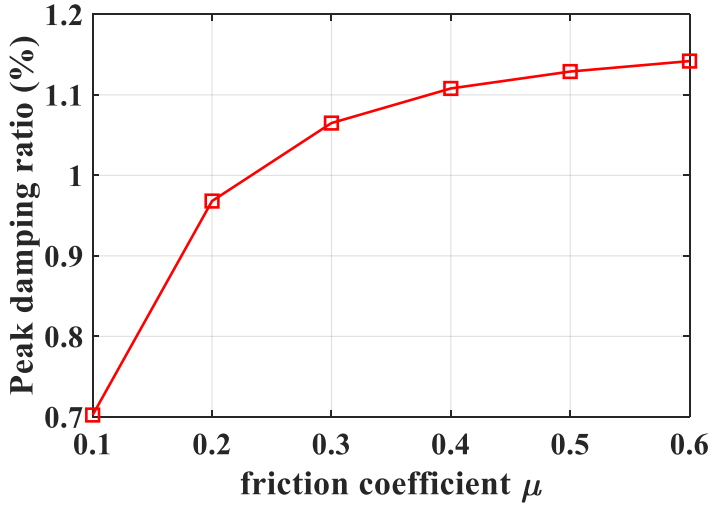

(b)

Figure 25. Damping evaluation with variation of friction coefficient: (a) Critical vibration stress; (b) Peak damping ratio.

\section{Conclusions}

In this paper, a method for analyzing the damping characteristics of shrouded turbine blades is proposed, which takes into account the variation of the contact equivalent stiffness of the shroud. A 2D contact model with variable normal force is adopted, and the influence of separation state on equivalent stiffness is considered. The curve of equivalent stiffness with amplitude is calculated. Then, the damping characteristic curve of shrouds, that is, the relationship of the equivalent damping ratio with vibration stress is calculated by the energy method. The design objective of this method is to provide a larger damping ratio under the allowable vibration stress. Based on ordinary modal analysis, this method is simple and time-saving, which is effectively useful in the design stage.

The 3ND 1B mode of bladed disk is taken as an example. When considering the influence of shroud separation on equivalent stiffness, with the increase of blade amplitude, the equivalent stiffness will gradually decrease to half of the original. Under the same vibration stress, the damping ratio of $2 \mathrm{D}$ contact model with variable equivalent stiffness method is lower than that of $2 \mathrm{D}$ contact model with constant stiffness method because 
there is no friction energy consumption in the separation stage, but it is still higher than that of $1 \mathrm{D}$ contact model.

In the 2D contact model, the phase angle between normal and tangential motion will significantly affect the damping characteristic curve, and there is no obvious law. With the rising of contact stiffness, the critical vibration stress descends and the peak damping ratio ascends. Under the allowable vibration stress of the blade, the initial contact normal force has an optimal value, which makes the damping ratio of the system maximum. The critical vibration stress and peak damping ratio first go up and then tend to be stable with the growing of friction coefficient.

Despite the fact the variation of the equivalent stiffness of the blade shroud is considered in this method, the linear mode of the bladed disk system is used directly, which leads to the expression of vibration displacement being only a single harmonic. In addition, in the actual vibration of the blade, if the amplitude is large, there will be slip, stick, and separation in the contact state during one cycle, which appear alternately in turn. In the actual vibration process, it is difficult to determine the mode of the structure. As mentioned earlier, some researchers $[19,20]$ put forward the concept of "nonlinear mode" to study the dynamic system with local nonlinearities. This paper uses the mode with altering stiffness to make some studies, which still make some assumptions. And the corresponding modes can be considered as one combination of the mode of the system with normal stiffness, that with three direction stiffness and free mode. This method does not consider the modes separately, but always uses the modes with stiffness in three directions, and through Fourier expansion, the influence of the three states is reflected as the variation of equivalent stiffness. However, the vibration form of the shrouded bladed disk still needs further study.

Author Contributions: Conceptualization, S.G.; methodology, S.G. and Y.W.; software, S.G.; WritingOriginal draft preparation, S.G.; Writing-Review and editing, Z.S. and S.C.; funding acquisition, Y.W. All authors have read and agreed to the published version of the manuscript.

Funding: This research was funded by the NSFC.

Acknowledgments: The authors would like to acknowledge Hang Ye's responses to the questions.

Conflicts of Interest: The authors declare no conflict of interest.

\section{Appendix A}

The 1D contact model describes the relationship between friction and 1D tangential relative displacement under constant normal force. The tangential contact stiffness is described by a spring of $k_{\mathrm{t}}$. The normal force $f_{\mathrm{c}, \mathrm{n}}=N_{0}$ on the contact surface makes the two objects contact all the time during the whole movement and the friction coefficient is $\mu$. Given the relative displacement between two contact nodes $\Delta u_{\mathrm{t}}$, the periodic tangential friction force $f_{\mathrm{c}, \mathrm{t}}$ can be calculated by using the relative displacement of slider $\Delta h_{\mathrm{t}}$. Two contact states, stick and slip, can be modeled. The contact law is described in time domain, and the friction force is expressed as:

$$
f_{c, t}(t)= \begin{cases}k_{\mathrm{t}}\left(\Delta u_{\mathrm{t}}(t)-\Delta h_{\mathrm{t}}(t)\right), & \text { stick } \\ \mu N_{0} \operatorname{sgn}\left(\Delta \dot{h}_{\mathrm{t}}(t)\right), & \text { slip }\end{cases}
$$

In the practical code, the predictor-corrector method is adopted, and the friction force is solved iteratively in discrete time steps. The friction force at this time step is solved according to the contact law, and then that at next time step is solved until the friction is stable. It usually takes several vibration periods, and the contact hysteresis loop can be stable. 
Firstly, assuming that the contact at the lth time step is in the stick state, the predictor of the friction at this time is:

$$
f_{\mathrm{c}, \mathrm{t}}^{\mathrm{pr}}(l)=k_{\mathrm{t}}\left(\Delta u_{\mathrm{t}}(l)-\Delta h_{\mathrm{t}}(l-1)\right)
$$

Then, the predicted friction force and Coulomb limit are compared to judge whether the current contact is stick or slip, and the force at $l$ th time step is corrected to:

$$
f_{c, t}(l)= \begin{cases}f_{\mathrm{c}, \mathrm{t}}^{\mathrm{pr}}(l), & \text { for }\left|f_{\mathrm{c}, \mathrm{t}}^{\mathrm{pr}}(l)\right|<\mu N_{0} \quad \text { (stick) } \\ \mu N_{0} \operatorname{sgn}\left(f_{\mathrm{c}, \mathrm{t}}^{\mathrm{pr}}(l)\right), & \text { for }\left|f_{\mathrm{c}, \mathrm{t}}^{\mathrm{pr}}(l)\right| \geq \mu N_{0} \quad \text { (slip) }\end{cases}
$$

Finally, the displacement of the slider at $l$ th time step is updated to:

$$
\Delta h_{\mathrm{t}}(l)= \begin{cases}\Delta h_{\mathrm{t}}(l-1), & \text { stick } \\ \Delta u_{\mathrm{t}}(l)-f_{\mathrm{c}, \mathrm{y}}(l) / k_{\mathrm{t}}, & \text { slip }\end{cases}
$$

\section{Appendix B}

The similarity between the $2 \mathrm{D}$ and $1 \mathrm{D}$ contact models is that $1 \mathrm{D}$ tangential relative displacement is described. The difference is that in 2D model, normal force changes during vibration. The contact states of separation, stick and slip can be modeled. Based on the normal contact stiffness $k_{\mathrm{n}}$ and normal relative displacement $\Delta u_{\mathrm{n}}$, the normal force is expressed as:

$$
f_{\mathrm{c}, \mathrm{n}}(t)=\max \left(N_{0}+k_{\mathrm{n}} \Delta u_{\mathrm{n}}(t), 0\right)
$$

If $f_{\mathrm{c}, \mathrm{n}}$ is positive, the system is in contact state; otherwise, it is in separation state. And the friction force is:

$$
f_{c, t}(t)= \begin{cases}0, & \text { separation } \\ k_{\mathrm{t}}\left(\Delta u_{\mathrm{t}}(t)-\Delta h_{\mathrm{t}}(t)\right), & \text { stick } \\ \mu f_{c, n}(t) \operatorname{sgn}\left(\Delta \dot{h}_{\mathrm{t}}(t)\right), & \text { slip }\end{cases}
$$

The expression of the iterative solution of predictor-corrector method in discrete time step is also given. The normal force at the lth time step is:

$$
f_{\mathrm{c}, \mathrm{n}}(l)=\max \left(N_{0}+k_{\mathrm{n}} \Delta u_{\mathrm{n}}(l), 0\right)
$$

The friction force at the lth time step is predicted to:

$$
f_{\mathrm{c}, \mathrm{t}}^{\mathrm{pr}}(l)=k_{\mathrm{t}}\left(\Delta u_{\mathrm{t}}(l)-\Delta h_{\mathrm{t}}(l-1)\right)=k_{\mathrm{t}}\left(\Delta u_{\mathrm{t}}(l)-\Delta u_{\mathrm{t}}(l-1)\right)+f_{\mathrm{c}, \mathrm{t}}(l-1)
$$

assuming that the contact is in the stick state. According to different contact state, the friction force is corrected to:

$$
f_{c, t}(l)=\left\{\begin{array}{lll}
0, & \text { for } f_{\mathrm{c}, \mathrm{n}}(l)=0 & \text { (separation) } \\
f_{\mathrm{c}, \mathrm{t}}^{\mathrm{pr}}(l), & \text { for }\left|f_{\mathrm{c}, \mathrm{t}}^{\mathrm{pr}}(l)\right|<\mu f_{\mathrm{c}, \mathrm{n}}(l) & \text { (stick) } \\
\mu f_{\mathrm{c}, \mathrm{n}}(l) \operatorname{sgn}\left(f_{\mathrm{c}, \mathrm{t}}^{\mathrm{pr}}(l)\right), & \text { for }\left|f_{\mathrm{c}, \mathrm{t}}^{\mathrm{pr}}(l)\right| \geq \mu f_{\mathrm{c}, \mathrm{n}}(l) & \text { (slip) }
\end{array}\right.
$$

The displacement of the slider is updated to:

$$
\Delta h_{\mathfrak{t}}(l)= \begin{cases}\Delta u_{\mathfrak{t}}(l), & \text { separation } \\ \Delta h_{\mathrm{t}}(l-1), & \text { stick } \\ \Delta u_{\mathfrak{t}}(l)-f_{\mathrm{c}, \mathrm{t}}(l) / k_{\mathrm{t}}, & \text { slip }\end{cases}
$$




\section{References}

1. Srinivasan, A.V. Flutter and Resonant Vibration Characteristics of Engine Blades. J. Eng. Gas Turbines Power 1997, 119, 742-775. [CrossRef]

2. Ewins, D.J. Control of Vibration and Resonance in Aero Engines and Rotating Machinery-An Overview. Int. J. Press. Vessel. Pip. 2010, 87, 504-510. [CrossRef]

3. Krack, M.; Salles, L.; Thouverez, F. Vibration Prediction of Bladed Disks Coupled by Friction Joints. Arch. Comput. Methods Eng. 2017, 24, 589-636. [CrossRef]

4. Bograd, S.; Reuss, P.; Schmidt, A.; Gaul, L.; Mayer, M. Modeling the Dynamics of Mechanical Joints. Mech. Syst. Signal Process. 2011, 25, 2801-2826. [CrossRef]

5. Marques, F.; Flores, P.; Pimenta Claro, J.C.; Lankarani, H.M. A Survey and Comparison of Several Friction Force Models for Dynamic Analysis of Multibody Mechanical Systems. Nonlinear Dyn. 2016, 86, 1407-1443. [CrossRef]

6. Griffin, J.H. Friction Damping of Resonant Stresses in Gas Turbine Engine Airfoils. J. Eng. Power 1980, 102, 329-333. [CrossRef]

7. Yang, B.D.; Chu, M.L.; Menq, C.H. Stick-Slip-Separation Analysis and Non-linear Stiffness and Damping Characterization of Friction Contacts Having Variable Normal Load. J. Sound Vib. 1998, 210, 461-481. [CrossRef]

8. Sanliturk, K.Y.; Ewins, D.J. Modelling Two-Dimensional Friction Contact and Its Application Using Harmonic Balance Method. J. Sound Vib. 1996, 193, 511-523. [CrossRef]

9. Yang, B.D.; Menq, C.H. Characterization of 3D Contact Kinematics and Prediction of Resonant Response of Structures Having 3D Frictional Constraint. J. Sound Vib. 1998, 217, 909-925. [CrossRef]

10. Menq, C.H.; Griffin, J.H.; Bielak, J. The Influence of a Variable Normal Load on the Forced Vibration of a Frictionally Damped Structure. J. Eng. Gas Turbines Power 1986, 108, 300-305. [CrossRef]

11. Phadke, R.; Berger, E.J. Friction Damping Analysis in Turbine Blades Using a User-Programmed Function in Ansys. In Proceedings of the 12th International Symposium on Transport Phenomena and Dynamics of Rotating Machinery, Honolulu, HI, USA, 17-22 February 2008.

12. Cardona, A.; Lerusse, A.; Géradin, M. Fast Fourier Nonlinear Vibration Analysis. Comput. Mech. 1998, 22, 128-142. [CrossRef]

13. Cameron, T.M.; Griffin, J.H. An Alternating Frequency/Time Domain Method for Calculating the Steady-State Response of Nonlinear Dynamic Systems. J. Appl. Mech. 1989, 56, 149-154. [CrossRef]

14. Zhang, D.; Fu, J.; Zhang, Q. An Effective Numerical Method for Calculating Nonlinear Dynamics of Structures with Dry Friction: Application to Predict the Vibration Response of Blades with Underplatform Dampers. Nonlinear Dyn. 2017, 88, 223-237. [CrossRef]

15. Kaneko, Y. Vibration Response Analysis of Mistuned Bladed Disk with Platform Damper: Effect of Friction Force Deviation on Vibration Characteristics. In Proceedings of the ASME Turbo Expo 2017: Turbine Technical Conference and Exposition, Charlotte, NC, USA, 26-30 June 2017.

16. Pesek, L.; Pust, L.; Snabl, P. Dry-Friction Damping in Vibrating Systems, Theory and Application to the Bladed Disc Assembly. In Nonlinear Structural Dynamics and Damping; Jauregui, J.C., Ed.; Springer International Publishing: Cham, Switzerland, 2019.

17. Mehrdad, P.S.; Zucca, S. A Reduced Order Model for Nonlinear Dynamics of Mistuned Bladed Disks with Shroud Friction Contacts. J. Eng. Gas Turbines Power 2018, 141, 11031. [CrossRef]

18. Petrov, E.P. A High-accuracy Model Reduction for Analysis of Nonlinear Vibrations in Structures with Contact Interfaces. J. Eng. Gas Turbines Power 2011, 133, 102503. [CrossRef]

19. Krack, M.; Panning, L.; Wallaschek, J. A Method for Nonlinear Modal Analysis and Synthesis: Application to Harmonically Forced and Self-excited Mechanical Systems. J. Sound Vib. 2013, 332, 6798-6814. [CrossRef]

20. Krack, M. Nonlinear Modal Analysis of Nonconservative Systems: Extension of the Periodic Motion Concept. Comput. Struct. 2015, 154, 59-71. [CrossRef]

21. Förster, A.; Panning, L.; Wallaschek, J. Equivalent Linearization of Bladed Disk Assemblies with Friction Nonlinearities Under Random Excitation. In Proceedings of the ASME Turbo Expo 2020: Turbomachinery Technical Conference and Exposition, Virtual Conference, Online, 21-25 September 2020.

22. Nan, G.; Lou, J.; Song, C. A New Approach for Solving Rub-Impact Dynamic Characteristics of Shrouded Blades Based on Macroslip Friction Model. Shock Vib. 2020, 2020, 8147143. [CrossRef]

23. Hüls, M.; Panning, L.; Wallaschek, J. Influence of Geometric Design Parameters onto Vibratory Response and High-Cycle Fatigue Safety for Turbine Blades with Friction Damper. J. Eng. Gas Turbines Power 2018, 141, 41022. [CrossRef]

24. Thomas, D.L. Dynamics of Rotationally Periodic Structures. Int. J. Numer. Methods Eng. 1979, 14, 81-102. [CrossRef]

25. Petrov, E.P. A Method for Use of Cyclic Symmetry Properties in Analysis of Nonlinear Multiharmonic Vibrations of Bladed Disks. J. Turbomach. 2004, 126, 175-183. [CrossRef]

26. Szwedowicz, J.; Sextro, W.; Visser, R.; Masserey, P.A. On Forced Vibration of Shrouded Turbine Blades. In Proceedings of the ASME Turbo Expo 2003, collocated with the 2003 International Joint Power Generation Conference, Atlanta, GA, USA, 16-19 June 2003.

27. Johnson, K.L. Contact Mechanics; Cambridge University Press: Cambridge, UK, 1985.

28. Rao, S.S. Mechanical Vibrations, 5th ed.; Prentice Hall: Upper Saddle River, NJ, USA, 2011.

29. Deutsch, F. Best Approximation in Inner Product Spaces; Springer: New York, NY, USA, 2001. 
30. Afzal, M.; Lopez, A.I.; Kari, L. Numerical Analysis of Multiple Friction Contacts in Bladed Disks. Int. J. Mech. Sci. 2018, 137, 224-237. [CrossRef]

31. Krack, M.; Panning, L.; Wallaschek, J.; Siewert, C.; Hartung, A. Reduced Order Modeling Based on Complex Nonlinear Modal Analysis and Its Application to Bladed Disks With Shroud Contact. J. Eng. Gas Turbines Power 2013, 135, 102502. [CrossRef] 